\title{
Presynaptic Calcium Channel Localization and Calcium- Dependent Synaptic Vesicle Exocytosis Regulated by the Fuseless Protein
}

\author{
A. Ashleigh Long, ${ }^{1}$ Eunju Kim, ${ }^{2}$ Hung-Tat Leung, ${ }^{2}$ Elvin Woodruff III, ${ }^{1}$ Lingling An, ${ }^{3}$ R. W. Doerge, ${ }^{3}$ William L. Pak, ${ }^{2}$ \\ and Kendal Broadie ${ }^{1}$ \\ ${ }^{1}$ Department of Biological Sciences, Kennedy Center for Research on Human Development, Vanderbilt University, Nashville, Tennessee 37235-1634, and \\ Departments of ${ }^{2}$ Biological Sciences and ${ }^{3}$ Statistics, Purdue University, West Lafayette, Indiana 47907
}

\begin{abstract}
A systematic forward genetic Drosophila screen for electroretinogram mutants lacking synaptic transients identified the fuseless ( fusl) gene, which encodes a predicted eight-pass transmembrane protein in the presynaptic membrane. Null fusl mutants display $>75 \%$ reduction in evoked synaptic transmission but, conversely, an approximately threefold increase in the frequency and amplitude of spontaneous synaptic vesicle fusion events. These neurotransmission defects are rescued by a wild-type fusl transgene targeted only to the presynaptic cell, demonstrating a strictly presynaptic requirement for Fusl function. Defects in FM dye turnover at the synapse show a severely impaired exo-endo synaptic vesicle cycling pool. Consistently, ultrastructural analyses reveal accumulated vesicles arrested in clustered and docked pools at presynaptic active zones. In the absence of Fusl, calcium-dependent neurotransmitter release is dramatically compromised and there is little enhancement of synaptic efficacy with elevated external $\mathrm{Ca}^{2+}$ concentrations. These defects are causally linked with severe loss of the Cacophony voltage-gated $\mathrm{Ca}^{2+}$ channels, which fail to localize normally at presynaptic active zone domains in the absence of Fusl. These data indicate that Fusl regulates assembly of the presynaptic active zone $\mathrm{Ca}^{2+}$ channel domains required for efficient coupling of the $\mathrm{Ca}^{2+}$ influx and synaptic vesicle exocytosis during neurotransmission.
\end{abstract}

Key words: Drosophila; photoreceptor; synapse; synaptic vesicle; exocytosis; neuromuscular junction

\section{Introduction}

The calcium influx triggering neurotransmission occurs via voltage-gated calcium channels clustered at presynaptic active zones. Vesicular exocytosis is driven by the rapid ( $<1 \mathrm{~ms})$ elevation of calcium concentration ( $>1000$-fold) within the presynaptic bouton (Dodge and Rahamimoff, 1967). High $\left[\mathrm{Ca}^{2+}\right] \mathrm{mi}-$ crodomains are generated by the opening of calcium channels directly tethered to docked synaptic vesicles, poised to fuse with the presynaptic membrane (Del Castillo and Katz, 1954; Katz and Miledi, 1965; Llinas et al., 1992; Horrigan and Bookman, 1994; Becherer et al., 2003; Demuro and Parker, 2006). Any disruption of these localized $\mathrm{Ca}^{2+}$ spikes significantly impairs vesicle exocytosis to interfere with the efficacy of basal synaptic transmission as well as $\mathrm{Ca}^{2+}$-dependent modulation.

Biochemical and genetic approaches have led to the identifi-

Received Dec. 15, 2007; revised Feb. 29, 2008; accepted March 1, 2008.

This work was supported by National Institutes of Health Grants GM54544 (K.B.), EY00033 (W.L.P.), and MH07504 (K.B., R.W.D., W.L.P.). We are particularly grateful to Richard Ordway (Pennsylvania State University, University Park, PA) for the UAS-Cac-GFP transgenic line, and John Merriam (University of California, Los Angeles, Los Angeles, (A) for the gift of a fus/ allele from his screen. We gratefully acknowledge the Bloomington Drosophila Stock Center and lowa Hybridoma Bank for important genetic and antibody reagents. We thank Gregore Koliantz, Julie Tseng-Crank, Erik Harness, Juko Kitamoto, and Ping Liang for technical assistance, and Jeff Rohrbough and Emma Rushton for advice and insightful comments on this manuscript.

Correspondence should be addressed to Prof. Kendal Broadie, Department of Biological Sciences, Vanderbilt University, VU Station B, Box 351634, Nashville, TN 37235-1634. E-mail: kendal.broadie@vanderbilt.edu.

D0I:10.1523/JNEUROSC1.5553-07.2008

Copyright $\odot 2008$ Society for Neuroscience $\quad$ 0270-6474/08/283668-15\$15.00/0 cation of presynaptic proteins linking $\mathrm{Ca}^{2+}$ dynamics with the synaptic vesicle (SV) cycle (Chen et al., 2001; Farsad and De Camilli, 2002; Rizo and Sudhof, 2002; Khvotchev et al., 2003; Takamori et al., 2006). Drosophila genetic screens have made important contributions to our understanding of this $\mathrm{Ca}^{2+}$ driven machinery. A screen for defective courtship identified mutants in cacophony (cac), encoding a $\mathrm{Ca}^{2+}$ channel $\alpha 1$ subunit, which exhibit reduced synaptic efficacy (Von Schilcher, 1976; Kawasaki et al., 2000, 2004; Xing et al., 2005). A screen for defective locomotion identified mutants in frequenin ( freq) (NCS-1), encoding an EF-hand $\mathrm{Ca}^{2+}$ sensor, which exhibits reduced $\mathrm{Ca}^{2+}$-dependent exocytosis and facilitation (Pongs, 1993; Bourne et al., 2001; Wang et al., 2001; Pan et al., 2002; Tsujimoto et al., 2002; Sippy et al., 2003). Drosophila mutants of synaptotagmin $I$, an integral SV $\mathrm{Ca}^{2+}$-binding protein, display $>75 \%$ reduced evoked neurotransmitter release and elevated spontaneous SV fusion, which helped establish the hypothesis that Synaptotagmin acts as a $\mathrm{Ca}^{2+}$ sensor synchronizing fast exocytosis (Littleton et al., 1993; Broadie et al., 1994; DiAntonio and Schwarz, 1994; Geppert et al., 1994; Yoshihara and Littleton, 2002). Mutants in Drosophila unc-13, a protein with C2 and C1 domains, display blocked SV fusion and arrested docked SVs at active zones, which helped establish the hypothesis that UNC-13 regulates SV priming (Aravamudan et al., 1999; Aravamudan and Broadie, 2003; Speese et al., 2003).

To identify new synaptic components, we performed Dro- 
sophila screens isolating synaptic mutants in the visual system using electroretinogram recordings (Pak, 1975; Burg et al., 1993). Because photoreceptor synapses are intractable for functional assays, detailed analyses were performed at the accessible neuromuscular junction (NMJ). The fuseless ( fusl) mutants display dramatically impaired transmission at both photoreceptor and NMJ synapses. Neurotransmission defects are rescued by targeted presynaptic expression of a fusl transgene, confirming gene identity and specific presynaptic requirement. The fuseless gene encodes a predicted eight-pass transmembrane protein of the presynaptic membrane, which regulates the localization of $\mathrm{Ca}-$ cophony $\mathrm{Ca}^{2+}$ channels to presynaptic active zones. Consistent with the loss of the $\mathrm{Ca}^{2+}$ trigger for SV exocytosis, fusl mutants show a severe reduction in SV cycling, as measured via lipophilic dye imaging, and a great elevation in the number of SVs clustered around active zones and docked with the presynaptic membrane poised for fusion, as shown by ultrastructural analyses. These data demonstrate that Fusl functions in the presynaptic membrane to facilitate localized expression of $\mathrm{Ca}^{2+}$ channels in active zone domains and that this activity is required for efficient synaptic vesicle exocytosis.

\section{Materials and Methods}

Second chromosome mutagenesis scheme. The second chromosome mutagenesis was done with an Oregon-R (OR) wild-type stock isogenized for the second chromosome and a dominant temperature-sensitive lethal mutation on the second chromosome, DTS-2 (Suzuki and Procunier, 1969). Wild-type males were fed $25 \mathrm{~mm}$ ethyl methane sulfonate (EMS) in $1 \%$ sucrose for $18 \mathrm{~h}$ (Ohnishi, 1977) and mated to virgin females carrying the DTS-2 second chromosome over the second chromosome balancer, SM5, marked with Curly (Cy) (Lindsley and Zimm, 1992) (see Fig. 1A). From the offspring of this cross, males carrying the mutagenized second chromosome over DTS- 2 were selected and single-male mated to virgin females of the DTS-2/SM5 Cy stock. Raising the temperature to $29^{\circ} \mathrm{C}$ killed DTS-2-carrying offspring of this cross (see Fig. $1 \mathrm{~A}$, $\mathrm{F}_{2}$ ), and the only surviving offspring were those carrying the mutagenized second chromosome over the SM5 balancer. Mating flies inter $S E$ generated offspring that are either homozygous or heterozygous for the mutagenized second chromosome (see Fig. $1 \mathrm{~A}, \mathrm{~F}_{3}$ ). These flies were tested directly for mutant phenotypes by ERG recording (see Fig. $1 B$ ). For recessive mutations, heterozygotes, which could be distinguished from homozygotes from the presence of $C y$ in the balancer chromosome, served as internal wild-type controls. Each line resulting from separate single-male mating in the $\mathrm{P}_{2}$ cross was considered a potential independent mutagenesis event. Lines that displayed mutant phenotypes for at least three generations were made homozygous and kept as mutant alleles.

Microarray analysis: RNA isolation, gene chip hybridization, and statistics. Three independent replicate RNA samples $(>5 \mu \mathrm{g})$ were prepared from isolated heads of each of the three fusl alleles and wild-type controls. Total RNA was extracted with the RNeasy Mini kit (Qiagen, Valencia, CA). Each RNA sample was checked for quality and concentration by $1 \%$ agarose-formaldehyde gel separation and a spectral scan in the 210-230 $\mathrm{nm}$ region. The Affymetrix (Santa Clara, CA) Drosophila genome array (Affymetrix GeneChip) version 2.0 was used in this work based on Drosophila Genome Annotation release 3.1 (released in 2003, Flybase; each chip contains 18,800 probe sets). The Purdue Genomics Core Facility processed the samples according to the Affymetrix protocol (http://www.affymetrix.com/ Auth/support/downloads/manuals/expression_s2_manual.pdf). Briefly, from total RNA, mRNA was reverse transcribed to $\mathrm{CDNA}$, and the resulting cDNA used to generate amplified biotin-labeled cRNA. cRNA was fragmented by heating and hybridized to the chip. An ANOVA was used to statistically test for differences in mRNA steady-state levels between mutants and the control using normalized data (Craig et al., 2003). It is necessary to adjust the type I error rate to accommodate multiple testing issues, using both the false discovery rate approach (Benjamini and Hochberg, 1995) and Holm's sequential Bonferroni correction procedure (Holm, 1979). The sig- nificance level was chosen as 0.05 . Genes falling within the mapped chromosomal limits of fusl were first identified. Statistical analysis of the microarray data provided the log-fold change in expression along with SDs and the $p$ value detected by probe sets corresponding to each gene. Candidate genes were identified as those with the largest log-fold changes (in absolute value) and with the lowest $p$ values. For sequencing candidate genes, primers were designed for several overlapping fragments encompassing the entire mRNA. RT-PCRs were done with the Qiagen Onestep RT-PCR kit and PCR fragments were electrophoresed on a $1 \%$ agarose gel and purified using the QIA-quick Gel Extraction kit (Qiagen). Each purified PCR fragment was paired with its own primers in separate sequencing reactions to determine both forward and reverse cDNA sequences.

Validation of gene identification: RNA interference. Double-stranded RNA was used to knock down the CG14021 gene by direct injection into the embryo (Lam and Thummel, 2000). Nonhomologous regions of CG14021 were identified; one such region being nucleotides 1227-1748 (accession number NM164640). First-strand cDNA was synthesized using Superscript III (Invitrogen, Carlsbad, CA) with oligo-dT primer. The template DNA for transcription reaction was amplified by PCR and used for the transcription reaction to synthesize the desired double-stranded RNA fragments (T7 RNA polymerase reaction kit; Ambion, Austin, TX). The synthesized RNA fragments were precipitated, washed with $70 \%$ $\mathrm{EtOH}$, and, after briefly air drying, dissolved into injection buffer $(5 \mathrm{~mm}$ $\mathrm{KCl}, 0.1 \mathrm{~mm} \mathrm{Na}_{2} \mathrm{PO}_{4}, \mathrm{pH} 6.8$ ) at $5 \mu \mathrm{M}$ concentration for injection.

Validation of gene identification: $c D N A$ and genomic rescue. The cDNA rescue construct used the GAL4-pUAST modular expression system (Brand and Perrimon, 1993). The enhanced green fluorescent protein (eGFP) coding sequence was fused to the CG14021 sequence in the construct for ready visualization of the gene product. CG14021 cDNA was generated using Superscript III reverse transciptase (Invitrogen) from total wild-type RNA. The CG14021 coding sequence (accession number NM164640; 857..2215) was amplified using PFU DNA polymerase (Stratagene, La Jolla, CA). The PCR product was subcloned into T-easy vector (Promega, Madison, WI) and cloned into the $p P\{U A S T\}$ vector at the EcoRI cloning site. The eGFP coding sequence was amplified by PCR using pIRES2-EGFP plasmid DNA as template, and the eGFP tag was fused in-frame at the $C$ terminus of the CG14021 coding sequence using the BglII and $K p n I$ sites. Transgenic flies carrying the $p P\{U A S T\}$ vector were generated by injection of the vector into $w^{1118}$; fusl ${ }^{1}$ mutant embryos. To activate the target sequence, these flies were crossed to those expressing GAL4 driven by either the Rh1 promoter for photoreceptorspecific expression or the elav promoter for neuron-specific expression. CG14021-eGFP fusion genes were used in genomic rescue constructs to enable localization of the CG14021 protein in transformants. The CG14021 gene encodes two transcripts RA and RB, generated by alternative splicing of the first intron (see Fig. $2 B$ ). The coding sequence is the same, but the noncoding first exons are located at two different locations several kilobases upstream of the coding sequence. Therefore, two different genomic constructs were generated corresponding to the two different transcripts. Immediately upstream of the smaller RA transcript is a 2 $\mathrm{kb}$ promoter region containing the TATA box, the insect transcription initiation site, and the $11 \mathrm{bp}$ conserved sequence for photoreceptor cell expression. For the larger RB transcript, the promoter was taken to be the $\sim 1 \mathrm{~kb}$ region between the CG14021 gene and the neighboring upstream gene CG12512. The sequences used were, in Flybase nucleotide coordinate units, 2L:5,330,871..5,338,053 for the smaller transcript and 2L: $5,330,871 . .5,339,224$ for the larger transcript (see Fig. 2 B). Each of these sequences, from which the stop codons and 3 '-untranslated regions had already been removed, was amplified in several fragments by PCR, linearized and cloned into the PstI and NotI sites of a modified $p P\{U A S T\}$ vector. The $p P\{U A S T\}$ vector was modified by removing the UAS promoter and cloning the eGFP coding sequence into its $K p n \mathrm{I}$ and $\mathrm{Xba \textrm {I }}$ cloning sites. Each of the two CG14021 genomic sequences was cloned into the modified vector to generate a vector containing in-frame fusion of eGFP coding sequence at the C-terminal end of the CG14021 genomic sequence. The two vectors along with fusl mutants were sent out to Rainbow Transgenic Flies (Newbury Park, CA) for generation of transgenic flies.

Fuseless antibody generation. A synthetic peptide corresponding to 
amino acid residues AMASFLIGGLGHFFF was used for immunization, and injected into two rabbits, following standard immunization protocols (Open Biosystems, Huntsville, AL). For epitope preservation, these antibodies work best with brief Bouin's (picric acid) fixative (15 min). The antibodies were used at a dilution of 1:100 in PBS-Triton X-100 (TX-100)-BSA, at which the concentration of TX-100 was $1 \%$ and BSA was $2 \%$. Antibodies were incubated overnight $(12 \mathrm{~h})$ at $4^{\circ} \mathrm{C}$. The secondary antibody Alexa Fluor 546 goat anti-rabbit (Invitrogen) was used at a dilution of 1:200 for $2 \mathrm{~h}$ at room temperature (RT).

Frozen cryosectioning of the visual system. The sectioning of Drosophila heads was done as described previously (Melzig et al., 1998). Heads from young adults were fixed for $2.5 \mathrm{~h}$ in an ice-cold solution containing $4 \%$ 1-ethyl-3,3-dimethylamino-propyl carbodi-imide (Sigma-Aldrich, St. Louis, $\mathrm{MO}$ ) in $67 \mathrm{~mm}$ phosphate buffer, $\mathrm{pH} 7.4$, and then washed overnight in $22.5 \%$ sucrose in PBS $\left(130 \mathrm{~mm} \mathrm{NaCl}, 7 \mathrm{~mm} \mathrm{Na}_{2} \mathrm{HPO}_{4}\right.$, and $3 \mathrm{~mm}$ $\mathrm{NaH}_{2} \mathrm{PO}_{4}, \mathrm{pH}$ 7.4). The heads were then embedded on small cryostat chucks with $18 \%$ carboxymethyl-cellulose, shock frozen in melting nitrogen, and sectioned at $10 \mu \mathrm{m}$ thickness on a cryostat microtome. The sections were blocked for $30 \mathrm{~min}$ in PBST (PBS, 0.05\% Triton X-100/4\% BSA) and incubated in anti-fusl antiserum in PBS (diluted 1:100) containing $4 \% \mathrm{BSA}$ overnight at $4^{\circ} \mathrm{C}$. After three PBST washes, specimens were incubated for $2 \mathrm{~h}$ at room temperature in goat anti-rabbit IgG labeled with Alexa Fluor 488 (Invitrogen) diluted 1:200 with PBS containing 4\% BSA. Specimens were washed three times in PBST, mounted with ProLong Gold Antifade Reagents (Invitrogen), and viewed on a Bio-Rad (Hercules, CA) MRC1024 confocal microscope (60×, $1.4 \mathrm{nu}-$ merical aperture lens; Nikon, Tokyo, Japan) using the Bio-Rad LaserSharp software. Acquired images were processed with Image J and Photoshop 7.0.

Immunohistochemistry at the neuromuscular junction. Wandering third instar larvae were dissected in standard Drosophila saline, fixed for 15 min in Bouin's fixative, washed for $30 \mathrm{~min}$ in PBS-TX-100, and stained with the primary antibodies for $4 \mathrm{~h}$ at RT. Presynaptic NMJ terminals were visualized with Texas Red-conjugated anti-horseradish peroxidase (HRP) (1:200; Invitrogen), which recognizes a neuronal membrane epitope. Staining of synaptic vesicles was done with Synaptotagmin I antibody (anti-rabbit; 1:500; gift from Dr. Hugo Bellen, Baylor College of Medicine, Houston, TX). Postsynaptic glutamate receptors were visualized using GluRIIA antibody (8B4D2; anti-mouse; 1:10; University of Iowa Developmental Studies Hybridoma Bank, Iowa City, IA). Secondary antibodies were Alexa 488 and Alexa 633 (1:200; Invitrogen) incubated for $2 \mathrm{~h}$ at RT. All images were taken on an upright Carl Zeiss (Jena, Germany) 510-Meta confocal microscope.

Electrophysiology: electroretinogram and intracellular recordings. Electroretinograms (ERGs) were recorded as previously described (Larivee et al., 1981). A 300 W halogen lamp (OSRAM, Munich, Germany) was used to generate light stimuli, which were delivered to the eye using a light guide (see Fig. $1 B$ ). Orange stimuli were generated by interposing a Corning (Corning, NY) CS2-73 filter in the light path. The stimulus intensity was attenuated in log-unit steps using Kodak (Rochester, NY) neutral density filters. Orange stimuli were used because they generate larger on-/off-transients than white light stimuli. The unattenuated intensity at the level of the eye was $830 \mu \mathrm{W} / \mathrm{cm}^{2}$. Both the recording and ground electrodes were filled with Hoyle's solution. The ground electrode was inserted into the head and the recording electrode was inserted through the cornea into the photoreceptor layer. The fly was darkadapted for 2 min before each stimulus, and all recordings were performed at $25^{\circ} \mathrm{C}$. Intracellular recordings were performed essentially as described by Johnson and Pak (1986). Briefly, a small cut was made on the head so as to cover a portion of the cornea and a part of the head. The cut was immediately sealed with vacuum grease to prevent fluid loss. Both the recording and ground electrodes were inserted through the cut with the recording electrode tip placed within the photoreceptor layer and the ground electrode tip very close to the photoreceptor layer. The recording electrode, filled with $2 \mathrm{M} \mathrm{KCl}$, had a resistance of 25-50 $\Omega$. The light source and the filters were the same as in ERG recordings. Signals were sampled at $2 \mathrm{kHz}$ with an analog-to-digital converter, and the data were acquired and analyzed with Axoscope software (Molecular Devices, Sunnyvale, CA).
Electrophysiology: two electrode voltage-clamp recordings. Electrophysiology at the wandering third instar NMJ was done using standard two electrode voltage-clamp (TEVC) techniques as described previously (Rohrbough et al., 1999). In brief, larvae were raised at $25^{\circ} \mathrm{C}$ and dissected dorsally in modified Drosophila saline containing additional sucrose (34 $\mathrm{mm}$ ) and $5 \mathrm{~mm}$ trehalose to prevent muscle vacuolization and to mimic conditions of the natural hemolymph as described (Stewart et al., 1994). Saline contained the following (in mM): $128 \mathrm{NaCl}, 2 \mathrm{KCl}, 4 \mathrm{MgCl}_{2}, 5$ trehalose, 70 sucrose, and $5 \mathrm{HEPES}$, and received appropriate volumes of $100 \mathrm{~mm} \mathrm{Ca}_{2} \mathrm{Cl}$ stock solution to make the $\left[\mathrm{Ca}^{2+}\right]$ indicated. Larvae were secured on sylgard-coated coverslips using surgical glue (Liquid Suture, Allentown, PA). Evoked excitatory junctional currents (EJCs) were stimulated with a glass suction electrode on the appropriate segmental nerve at a suprathreshold voltage level. Glutamate iontophoresis was performed as previously described (Featherstone et al., 2005). Briefly, glutamate (100 mm; $\mathrm{pH} 9)$ was pressure ejected from a small diameter $(10 \mu \mathrm{m})$ glass pipette and glutamate-gated currents recorded in TEVC. All current recordings were done in voltage-clamped muscle $\left(V_{\text {hold }}=-60 \mathrm{mV}\right)$ on muscle 6 (segment A3) with Axoclamp 200B (Molecular Devices) and analyzed with Clampex 7.0 software.

FM-143 dye imaging. Dye imaging studies were performed as described previously (Trotta et al., 2004). Briefly, wandering third instar animals were dissected in $1.8 \mathrm{~mm} \mathrm{Ca}^{2+}$ standard saline. Preparations were incubated with FM1-43 (10 $\mu \mathrm{M}$; Invitrogen) for $2 \mathrm{~min}$ in high $\left[\mathrm{K}^{+}\right]$ saline $(90 \mathrm{~mm}[\mathrm{NaCl}]$ reduced to $50 \mathrm{~mm})$ at RT. Preparations were then washed in buffered $0 \mathrm{mM} \mathrm{Ca}^{2+}$ saline for $2 \mathrm{~min}$. Images were acquired on a Carl Zeiss 510-Meta confocal microscope. The mean pixel fluorescence at individual NMJ boutons was determined using ImageQuant software (GE Healthcare, Little Chalfont, Buckinghamshire, UK). The mean pixel intensity of at least five single boutons was averaged for each NMJ, and two NMJs per animal were then averaged to generate a single data point. The vesicle cycle was stimulated again using the high $\left[\mathrm{K}^{+}\right]$, as above but without FM1-43, for 2 min to unload FM1-43 dye from the NMJ boutons and provide a measure of exocytosis efficacy. The degree of unloading was quantified in the same manner as that of the loading procedure. FM1-43 dye loading was also assayed using electrical motor nerve stimulation as previously described (Dermaut et al., 2005). In brief, the nerve was stimulated with a glass suction electrode at $30 \mathrm{~Hz}$ for 5 min with 10 $\mu \mathrm{M}$ FM1-43 in the bath. Preparations were then washed in buffered $0 \mathrm{mM}$ $\mathrm{Ca}^{2+}$ saline for 2 min. Loading was quantified using average mean pixel intensity per bouton as above.

Electron microscopy: ultrastructural analysis. Mutant ( fusl $^{1}$; fusl $^{l}$ and fusl $^{l} / \mathrm{Df}$ ) and control (wild-type OR-R and +/Df) wandering third instar larvae were fixed, sectioned, and visualized in parallel using standard transmission electron microscopic (TEM) techniques, as reported previously (Featherstone et al., 2001). Briefly, animals were dissected in $0.05 \mathrm{M}$ PBS and placed in $2.0 \%$ glutaraldehyde for $15 \mathrm{~min}$, replaced with fresh $2.0 \%$ glutaraldehyde for $1 \mathrm{~h}$. Preparations were washed in PBS (three times), transferred to $1 \% \mathrm{O}_{\mathrm{s}} \mathrm{O}_{4}$ in distilled water $\left(\mathrm{dH}_{2} \mathrm{O}\right)$ for $2 \mathrm{~h}$, and washed in $\mathrm{dH}_{2} \mathrm{O}$ (three times). Preparations were stained en bloc in $1 \%$ aqueous uranyl acetate for $1 \mathrm{~h}$, washed in $\mathrm{dH}_{2} \mathrm{O}$ (three times), dehydrated through an EtOH series $(30-100 \%)$, passed through propylene oxide, transferred to a 1:1 Araldite:propylene oxide mixture, and embedded in Araldite media. Ultrathin serial sections (50-60 nm) were obtained on a Leica (Wetzlar, Germany) UCT Ultracut microtome and transferred to Formvar-coated grids. Grids were examined on a Phillips CM10 TEM equipped with an AMT 2 mega pixel camera. Four animals from each genotype were processed. NMJs were sectioned, and profiles for each identified type I synaptic bouton were quantified in a section containing only a single prominent electron-dense active zone (AZ) T-bar. Synaptic vesicles in the "clustered" pool were defined as those $<250 \mathrm{~nm}$ of the AZ T-bar. Docked vesicles were defined as those $<0.5$ vesicle diameter $(<20 \mathrm{~nm})$ of the electron-dense plasma membrane at the AZ. Quantified measurements were made using Image J. Bouton and mitochondria area, number of docked, clustered, and total vesicles, and vesicle density (corrected for mitochondria area) were scored for each profile. Mean quantified parameters were statistically compared using the Mann-Whitney test, and presentation images were processed in Adobe Photoshop. 


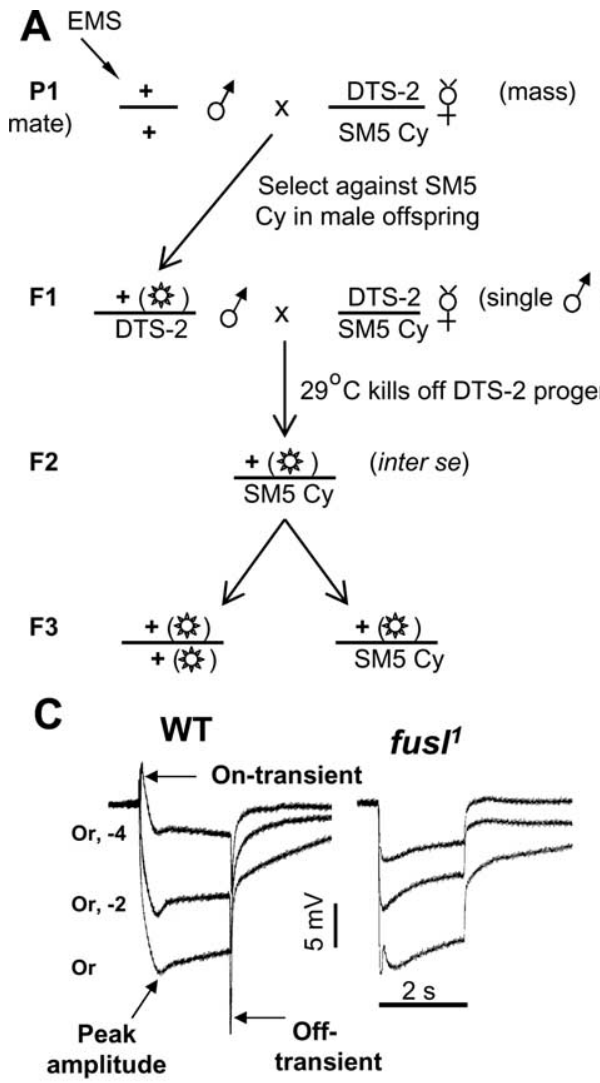

D

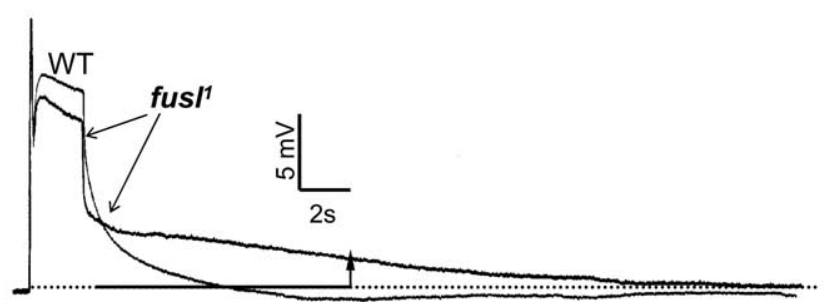

Figure 1. Phototransduction mutagenesis identifies a novel mutant specifically defective in synaptic transmission. $\boldsymbol{A}$, Second chromosome mutagenesis scheme. EMS mutagenized males were single-mated in a second generation cross to track each mutant line independently. The DTS-2 mutation allowed only animals carrying the mutagenized second chromosome over balancer to survive among $F_{2}$ offspring. Crossing inter SE produced offspring $\left(F_{3}\right)$ that are either homozygous or heterozygous for the mutagenized second chromosome. These animals were screened by ERG recording. $\boldsymbol{B}$, Diagram of ERG recording. The fly was mounted in low-melting-point wax, with a recording electrode in the cornea and a reference electrode in head. The light stimulus ( $300 \mathrm{~W}$ halogen lamp) was led to eye using an optical light guide. C, The fus/ mutants show a specific loss of ERG synaptic transients. Representative ERG traces (left) elicited from WT and fus/ using $2 \mathrm{~s}$ orange light stimuli. Responses at three different light intensities are shown superimposed. Synaptic on- and off-transients are absent in fus/ mutants. Right, Peak ERG and synaptic on-transient amplitudes (as defined in the left image) plotted against stimulus intensity for WT $(N=8)$ and fusI ( $N=9$ ). Error bars indicate SEM. $\boldsymbol{D}$, Representative photoreceptor intracellular recordings from WT and fusl, shown superimposed. The receptor potentials have indistinguishable amplitudes (WT, $23.8 \pm 2.7 \mathrm{mV}$; fusl, $22.5 \pm 2.1 \mathrm{mV})$ and time $(N=7)$. However, the fusl response is slowly decaying: WT has completely returned to baseline $[9.8 \pm 0.9 \mathrm{~s}(N=7)$ after stimulus termination], whereas the mutant response still displays a $2.0 \pm 0.8 \mathrm{mV}(N=7)$ depolarization (arrow).

Immunoelectron microscopy. Wandering third instar larvae carrying the fusl-GFP transgene in the fusl $l^{l} / f u s l^{l}$ null background were dissected and fixed as described above. Preparations were then processed through an anti-GFP immunocytochemical protocol to localize the Fusl fusion protein. Briefly, preparations were rinsed in PBS for $10 \mathrm{~min}$, and then taken through a graded methanol series $(50 \%$ for $10 \mathrm{~min}, 70 \%$ for 30 min) and embedded in LR White (1:1 LR White:fresh absolute EtOH, 30 min; 2:1 LR White:fresh absolute EtOH, 30 min; pure LR White, 1 h). Samples were changed to fresh LR White and let stand overnight while agitated. Samples were then embedded in fresh LR White in flatbottomed capsules (Ted Pella, Redding, CA; catalog \#133-P) with a disk of Aclar plastic (Ted Pella; catalog \#10501-10) used to make an optically clear surface at the bottom, and a square of Parafilm placed over the top, and sealed with a cap from a BEEM capsule (K. McDonald, personal communication). Using a staining plate (Electron Microscopy Sciences, Hatfield, PA; catalog \#71568), grids with $100 \mathrm{~nm}$ sections were placed into $40 \mu \mathrm{l}$ of blocking buffer for 30 $\mathrm{min}$. Wells from the next row were filled with a commercial anti-GFP antibody (Abcam, Cambridge, MA) in blocking buffer, and grids were transferred and incubated from $1 \mathrm{~h}$ to overnight in different trials. Grids were then rinsed in PBS-Tween for $2 \mathrm{~min}$, rinsed in PBS (four times; 2 min each), and incubated in secondary antibody in blocking buffer for 1-2 h. Grids were poststained with uranyl acetate and lead citrate for $3 \mathrm{~min}$, and then imaged as for regular electron microscopy. NMJ boutons were examined with a Phillips CM10 TEM equipped with an AMT 2 mega pixel camera, and images were processed in Adobe Photoshop.

Elav; UAS-Cac-GFP imaging and electrophysiology. To quantitatively assess voltage-gated calcium channels at the NMJ, the UAS-CacGFP transgenic line (kindly provided by Dr. Richard Ordway, Pennsylvania State University, University Park, PA) was crossed into control and fuseless null mutant backgrounds. The UAS-Cac-GFP transgene was then driven specifically in the motor neuron presynaptic terminal by crossing in the pan-neuronal elav GAL4 driver (Andrews et al., 2002; Trotta et al., 2004). Wandering third instars were dissected in modified Drosophila saline, as above. A NMJ was identified and type I boutons examined by confocal microscopy. TEVC was performed on controls (elav-GAL4;UAS-Cac-GFP in a wildtype background) and mutants ( fusl $l^{1} /$ fusl $^{l}$; elav-GAL4;UAS-Cac-GFP) as described above.

\section{Results}

Isolation of synaptic mutants by electroretinogram recording

An EMS chemical mutagenesis for synaptic mutants was performed targeting the second chromosome, which contains $\sim 36 \%$ of the Drosophila genome (Fig. $1 A)$. Males carrying an EMS-mutagenized second chromosome were singly mated in a second generation cross to isolate different strains. The dominant temperaturesensitive 2 (DTS2) mutation was used to select for the mutagenized second chromosome over balancer chromosome among $\mathrm{F}_{2}$ offspring (Fig. 1A). Crossing inter $S E$ produced $\mathrm{F}_{3}$ generation homozygous second chromosome mutants that were screened as adults for defects in synaptic transmission in the visual system.

The mutant screen was performed by direct ERG recording as diagramed in Figure $1 B$. The ERG is a light-evoked, extracellularly recorded mass response of the eye consisting of contributions from several different types of cells. During light stimulation, lights-on and lights-off ERG transients represent synaptic transmission in the visual system. From our screen, 16 mutant complementation groups on the second chromosome were identified based on grossly abnormal ERG responses. The majority of 
these mutants impact the phototransduction pathway directly (for review, see Pak, 1975, 1995; Pak and Leung, 2003). However, a "transientless" ERG phenotype characterized six mutant complementation groups, indicating a specific impairment in synaptic transmission. The fuseless ( $f u s l$ ) complementation group was one of these six, with two mutant alleles identified in the ERG screen and an additional allele obtained from John Merriam's group at University of California, Los Angeles (Los Angeles, CA) (Markow and Merriam, 1977).

\section{Fuseless is required for synaptic transmission in the visual system}

The ERG consists of a corneal-negative (downward), sustained component and two transient components at lights-on and lights-off (Fig. 1C). The sustained component reflects the summed phototransduction responses of photoreceptors. The onand off-transients arise from the lamina to which the majority class of photoreceptors (R1-6) synapse (for review, see Buchner, 1991; Pak, 1995). The on-transient, in particular, corresponds directly to the responses of laminar neurons to input from photoreceptors R1-6. As shown in Figure $1 C$, the sustained photoreceptor component of fusl mutants is normal in both amplitude and duration, but the synaptic on-/ off-transients present in the wild-type control are absent in fusl mutants. The peak amplitude of the phototransduction component and the synaptic on-transient were quantified and plotted as a function of the stimulus intensity (Fig. $1 C$, right). The fusl mutants display normal amplitude phototransduction responses at all stimulus intensities, but lack any detectable synaptic responses over the entire intensity range. Intracellular recordings from photoreceptors confirmed the normal amplitude and duration of photoreceptor potentials (Fig. 1D). However, the photoreceptor potential in fusl mutants displayed an aberrant, slowly decaying component (Fig. $1 D$ ). This depolarizing tail phenotype was specific to fusl mutants because a similar slowly decaying tail was not observed in other transientless synaptic mutant complementation groups. However, the slowly decaying tail does not detectably affect the amplitude and waveform of the photoreceptor potential during the period of light stimulus.

\section{Genomic and microarray analyses identify the fuseless gene}

Deficiency mapping showed that fusl is uncovered by deficiency $D f(2 L)$ Exel6012 and is covered (complemented) by deficiency $D f(2 L) c l 7$, localizing the fusl gene between the left breakpoint of Exel6012 and the left breakpoint of cl7 (Fig. 2A). Exel6012 breakpoints were defined at the molecular level, and the molecular coordinate of its left breakpoint is $2 \mathrm{~L}: 5,303,145$. The left breakpoint of deficiency $\mathrm{cl} 7$ is defined by the location of the nompC gene, which is either deleted or disrupted by $c 17$. According to
Affymetrix Drosophila microarray annotation, there are nine genes within the interval defined by these two breakpoints.

To identify the candidate fusl gene in the mapped interval, microarray analyses were performed on fusl mutants to screen for genes with altered mRNA levels. Microarrays were performed on the three alleles of fusl along with appropriate wild-type controls (data not shown). Of the nine genes in the mapped interval, the CG14021 gene displayed the most significant changes in mRNA levels for all three fusl mutant alleles. Specifically, the probe set for CG14021 detected log-fold changes of $-0.593(p=0),-0.895$ $(p=0)$, and $-0.559\left(p=3.8 \times 10^{-15}\right)$ in the three fusl alleles. Another gene in this interval, cype, also had low $p$ values although log-fold changes were only moderate. The log-fold changes and $p$ values for this gene were $-0.352(p=0),-0.459(p=0)$, and $+0.208(p=0)$. A third gene, vri, also had a fairly high log-fold change with a $p$ value of zero, but only in a single fusl allele $(-0.680 ; p=0)$. Log-fold changes were low $(0.26$ and -0.28$)$ and $p$ values were high $\left(3 \times 10^{-13}\right.$ and $\left.1.5 \times 10^{-6}\right)$ in the other two fusl alleles. The microarray analyses therefore revealed two candidate fusl genes, CG14021 and cype.

To distinguish between these two candidate genes, we se- 
quenced both in all three fusl alleles. Sequencing revealed no mutations in the cype gene in any of the three mutant alleles. The CG14021 gene, however, was found to carry stop codons in all three alleles (Fig. 2 B). Two of the allelic mutants turned out to be identical with a nonsense mutation (TGT $\rightarrow$ TGA) that terminates the protein at Cys(89). This allele is now designated fusl ${ }^{l}$. The other allele $\left(f u s l^{2}\right)$ also carries a nonsense mutation $(\mathrm{TGG} \rightarrow \mathrm{TAG})$ that truncates the protein at $\operatorname{Trp}(167)$. In addition, it carried a missense mutation $(\mathrm{CTC} \rightarrow \mathrm{CAC})$, which results in a Leu(34)His change. Identification of these mutations strongly indicated that CG14021 is the fuseless gene and that these mutations are responsible for the mutant phenotypes. Subsequent RNAi and transgenic rescue experiments (see below) confirmed that CG14021 is the fuseless gene.

Fuseless is a predicted eight-pass transmembrane transporter The fuseless (CG14021) gene encodes two transcripts, RA and RB, which differ in the first noncoding exons (and promoters) located at two different locations (Fig. 2 B). Upstream of the RA transcript is a $\sim 2 \mathrm{~kb}$ promoter region containing the TATA box, transcription initiation site, and the consensus $11 \mathrm{bp}$ conserved sequence for photoreceptor expression, suggesting that the RA isoform is expressed in photoreceptors. The coding sequences of the two fusl transcripts are identical and encode a protein of 453 aa, with eight predicted transmembrane regions, characteristic of a transporter (Fig. $2 \mathrm{~B}$ ). This is a novel protein derived from annotated genome sequences, and its function is not known. The most salient feature of the predicted protein is the presence of eight transmembrane domains (Fig. $2 B$ ). BLAST searches reveal that proteins most closely related to Fusl have been identified in several insect species (Apis mellifera, Anopheles gambiae, Drosophila pseudoobscura, Tribolium castaneum) (Fig. 2C). These proteins share $36 \%$ (Anopheles) to $81 \%$ (D. pseudoobscura) amino acid identity (51-87\% similarity) with the Fusl protein. Moreover, all four proteins share with Fusl the eight transmembrane domains at conserved locations. The Anopheles protein differs from the others slightly by having a ninth transmembrane domain at its $\mathrm{C}$ terminus. All of these proteins are novel and their function is unknown. The phylogenetic relationship between these proteins is shown in Figure 2C. Other proteins identified in BLAST searches shared with fuseless $\leq 21$ and $\leq 39 \%$ amino acid identity and similarity, respectively. Among these, the five proteins with the highest amino acid identity, and of comparable size to Fusl, are included in the phylogeny tree in Figure $2 C$. All of these proteins for which functions are known act as transmembrane transporters for various substrates. Indeed, four of the five proteins included in the phylogeny tree are known transporters, whereas the function is not known for the fifth protein (Fig. 2C). Thus, the eight transmembrane domains and the known transporter function of related proteins both suggest that the Fusl protein likely functions as a transmembrane transporter.

\section{Fuseless is a presynaptic plasma membrane protein in visual system and NMJ}

The above evidence suggests that Fusl in a multipass transmembrane protein required in the visual system for photoreceptor synaptic transmission. To test the predicted cellular distribution of the Fusl protein in the visual system, we generated a specific anti-Fusl peptide antibody (see Materials and Methods). In whole-mount preparations (Fig. $3 A$ ), anti-Fusl immunoreactivity labels the retinal photoreceptors, revealed with colabeling with the neuronal membrane epitope marker anti-HRP. To assay Fusl localization more precisely, frozen sections were made of the
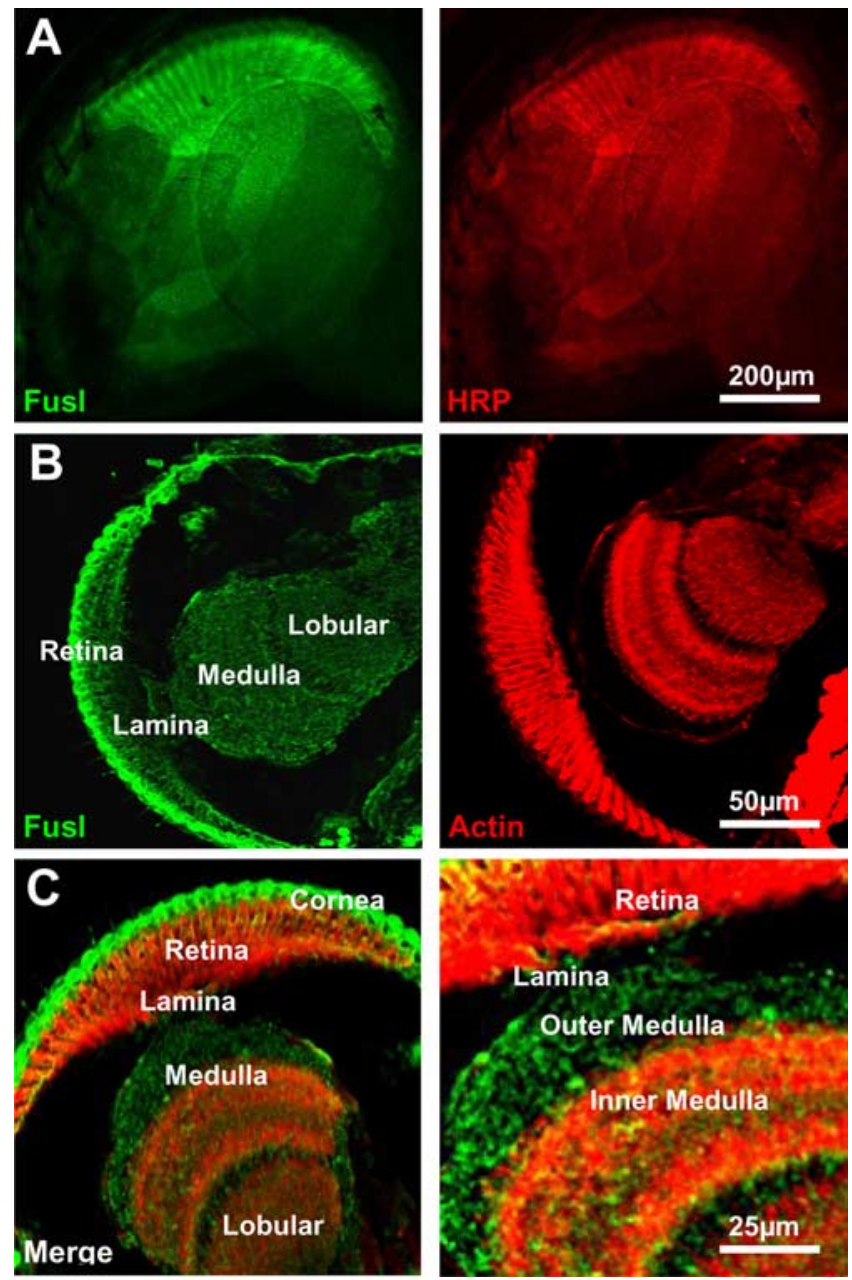

Figure 3. Fusl protein expression in the visual system. $\boldsymbol{A}$, Whole-mount preparation of the adult Drosophila eye, colabeled with anti-Fuseless (green; left) and anti-HRP (red; right), a neuronal plasma membrane marker. Scale bar, $200 \mu \mathrm{m}$. B, C, Cryosections of the adult visual system colabeled with anti-Fusl (green; left) and actin phalloidin (red; right). The sections shows retina, lamina, and medulla, as indicated. Scale bars: $\boldsymbol{B}, \boldsymbol{C}$, left, $50 \mu \mathrm{m}$; $\boldsymbol{C}$, right, $25 \mu \mathrm{m}$.

visual system. Staining with the Fusl antibody reveals expression in the retina, lamina, and medulla (Fig. 3B). Photoreceptor labeling is consistent with plasma membrane localization, with Fusl colocalizing with the membrane anti-HRP epitope. In the lamina and medulla, Fusl has a highly punctate expression pattern, consistent with synaptic localization (Fig. 3C). These results suggest that Fusl is an integral protein of the plasma membrane and may be enriched in synaptic termini.

The larval neuromuscular synaptic system has the bestcharacterized structure and molecular architecture in Drosophila, and was therefore used to study and synaptic expression and function of the Fusl protein in additional detail. Fusl expression was assayed at three levels: (1) with anti-Fusl antibody, (2) with a fusl-GFP transgene that rescues fusl mutant phenotypes (see below), and (3) at ultrastructural resolution with immunogold electron microscopy. Confocal imaging was used to examine the expression of antibodies raised against the native Fusl protein (Fig. $4 A-C)$. Anti-Fusl immunoreactivity is detectable only in the nervous system, without expression in other tissues, suggesting that Fusl is a neural-specific protein (Fig. 4A). This expression is lost in the fusl $^{l}$ mutant, confirming that this allele is a protein null and demonstrating the specificity of the antibody (Fig. 4B). Fusl is highly expressed within both the presynaptic nerve and in the 
plasma membrane surrounding boutons at the NMJ (Fig. $4 A, B$ ). The protein is very weakly or undetectably expressed in neuronal soma or proximal processes within the CNS (data not shown). Within the nerve and presynaptic NMJ arbors, Fusl colocalizes nearly identically with the presynaptic plasma membrane marker antiHRP (Fig. 4B,C). In high-magnification images of synaptic boutons, Fusl appears clearly membrane-associated and restricted to the outermost periphery of the bouton. Indeed, Fusl appears to localize more tightly with the plasma membrane than the classic membrane marker antiHRP (Fig. 4C), consistent with its being an integral plasma membrane protein. The distribution of EGFP-tagged-fuseless shows an identical pattern, with the protein concentrated in NMJ synaptic boutons and highly enriched at the plasma membrane of the bouton periphery (Fig. $4 D)$. Both techniques show that Fusl is not restricted to active zones, or to any type of localized membrane domain, but rather shows a general presynaptic neuronal membrane localization. To examine Fusl localization as precisely as possible, immunoelectron microscopy was next used to image the EGFP-tagged-fuseless (Fig. 4E). Ultrastructurally, the Fusl protein was found to be restricted to the extreme periphery of synaptic boutons and to be membrane associated, consistent with confocal imaging and protein predictions. The gold label was observed within and immediately adjacent to the presynaptic plasma membrane (Fig. $4 E$, arrows) but was also observed associated with vesicle membranes within $<250 \mathrm{~nm}$ of the plasma membrane (Fig. $4 E$, top). The Fusl protein was observed in close association with presynaptic active zones, but it was not restricted to active zones and showed a general presynaptic membrane distribution. This imaging is consistent with a plasma membrane localized protein (Lnenicka et al., 2006) and also consistent with the eight-pass transmembrane structure of the Fusl protein (Fig. 2 B).

Impaired presynaptic function may arise from many causes, including defects in the architectural or molecular differentiation of the presynaptic terminal. To test these possibilities, NMJ structure and molecular composition were systematically compared between fusl null mutants and controls (Fig. 4) (data not shown). The fusl mutant does not show any detectable defects in the gross architecture of the neuromusculature, with normal motor nerve trajectories, normal muscle anatomy and normally placed and differentiated NMJs. NMJ structure was examined using antiHRP labeling to reveal the presynaptic neuronal membrane. No defects were observed in NMJ placement, size, branching, or synaptic bouton formation (Fig. $4 \mathrm{~B}$ ). No detectable differences were observed in fusl null mutants in the localization, area, or mean fluorescence intensities of presynaptic markers, such as the inte-
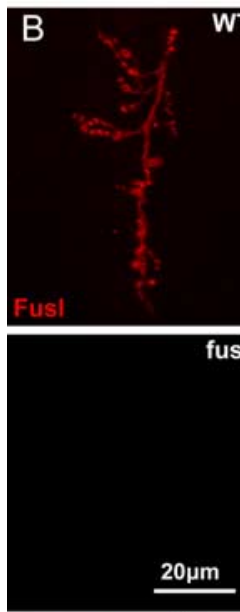
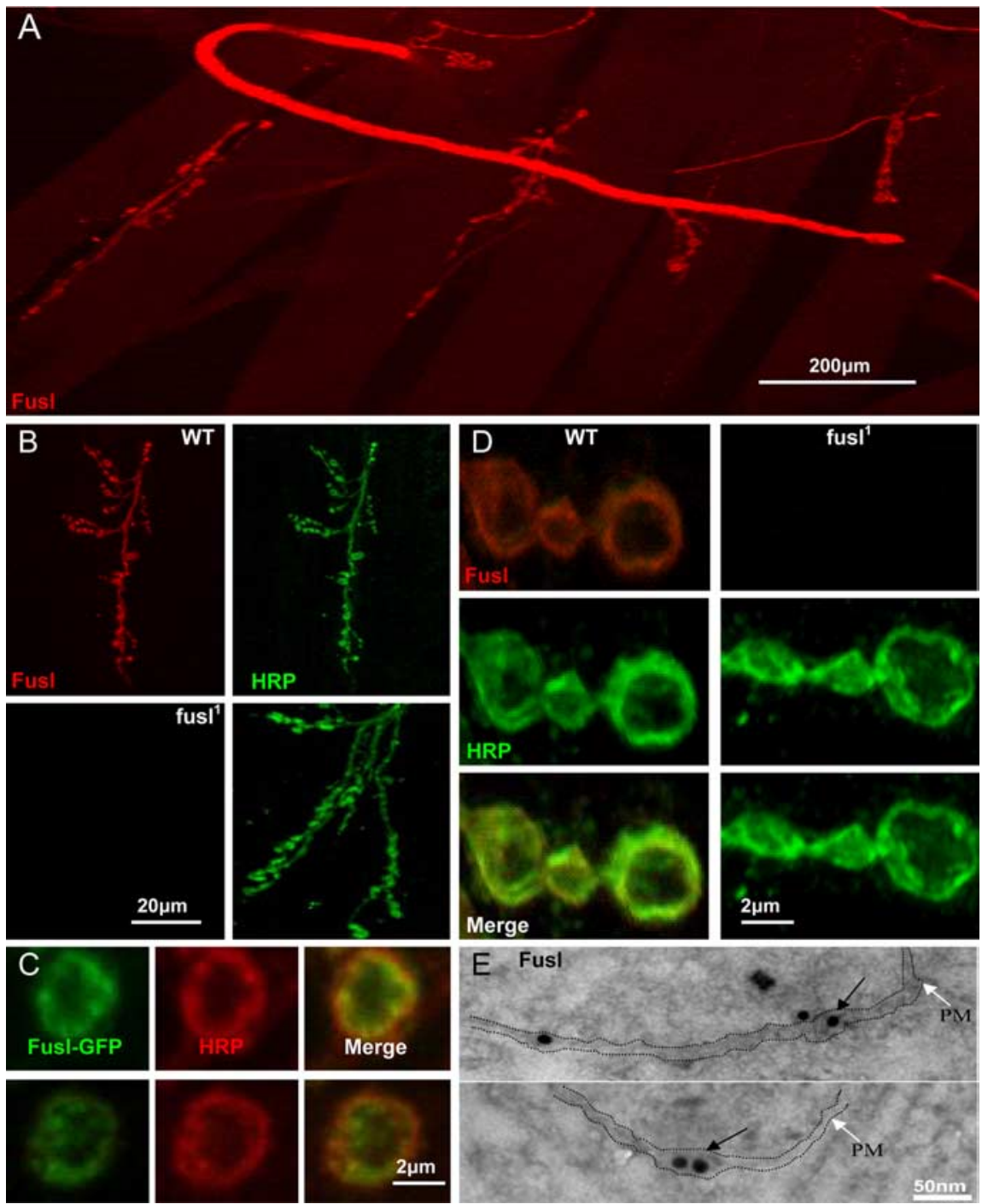

Figure 4. Fusl protein localizes in the presynaptic plasma membrane. $\boldsymbol{A}$, Very low magnification image of the neuromusculature. Anti-Fusl immunoreactivity observed only in presynaptic nerve and NMJ synapses. Scale bar, $200 \mu \mathrm{m}$. B, Low magnification anti-Fusl (red). The WT control is show on top, and the fusl ${ }^{7}$; fusl' mutant on the bottom. Scale bar, $20 \mu \mathrm{m}$. C, High magnification mages of individual NMJ synaptic boutons in control (left) and mutant (right). Fusl is restricted to the plasma membrane. Scale bar, $2 \mu \mathrm{m}$. D, The transgenic Fusl-GFP fusion protein colocalizes with anti-HRP in synaptic boutons, revealing a peripheral, plasma membrane associated localization. Scale bar, $2 \mu \mathrm{m}$. $\boldsymbol{E}$, Fusl-GFP distribution by immuno-EM. Anti-GFP with an electron-dense gold ( $15 \mathrm{~nm}$ immunogold) label visualized by TEM. Gold label (arrows) observed in and immediately adjacent to the presynaptic plasma membrane (PM) in the NMJ bouton. Scale bar, $50 \mathrm{~nm}$.

gral synaptic vesicle protein Synaptotagmin 1, or postsynaptic glutamate receptors (data not shown). These data show that Fusl is not required for synaptic morphogenesis or the gross molecular differentiation of presynaptic and postsynaptic compartments.

\section{Fuseless regulates glutamatergic synapse function}

The larval glutamatergic NMJ synapse is by far the best-defined model synapse in the Drosophila system, and was therefore used to systematically characterize the role of Fusl in synaptic mechanisms. Any significant impairment in larval NMJ function should first be revealed by compromised coordination and/or locomotion. Two larval behavioral assays were conducted to assess coordination (eating pharyngeal movements) and locomotion (body wall contractions) (Fig. 5A). All fusl mutant alleles showed a clear and obvious impairment in both of these behaviors compared 
A

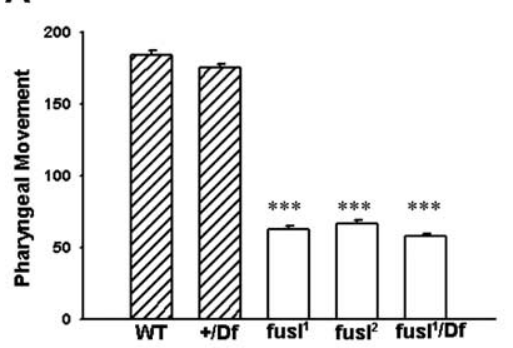

B

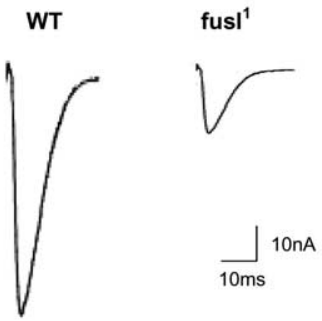

C
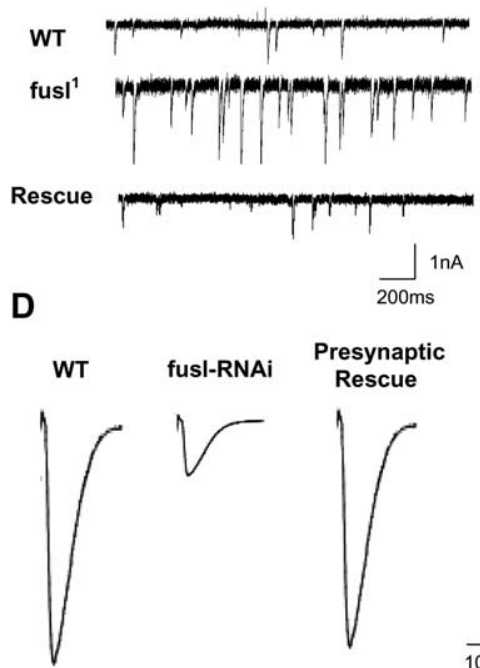
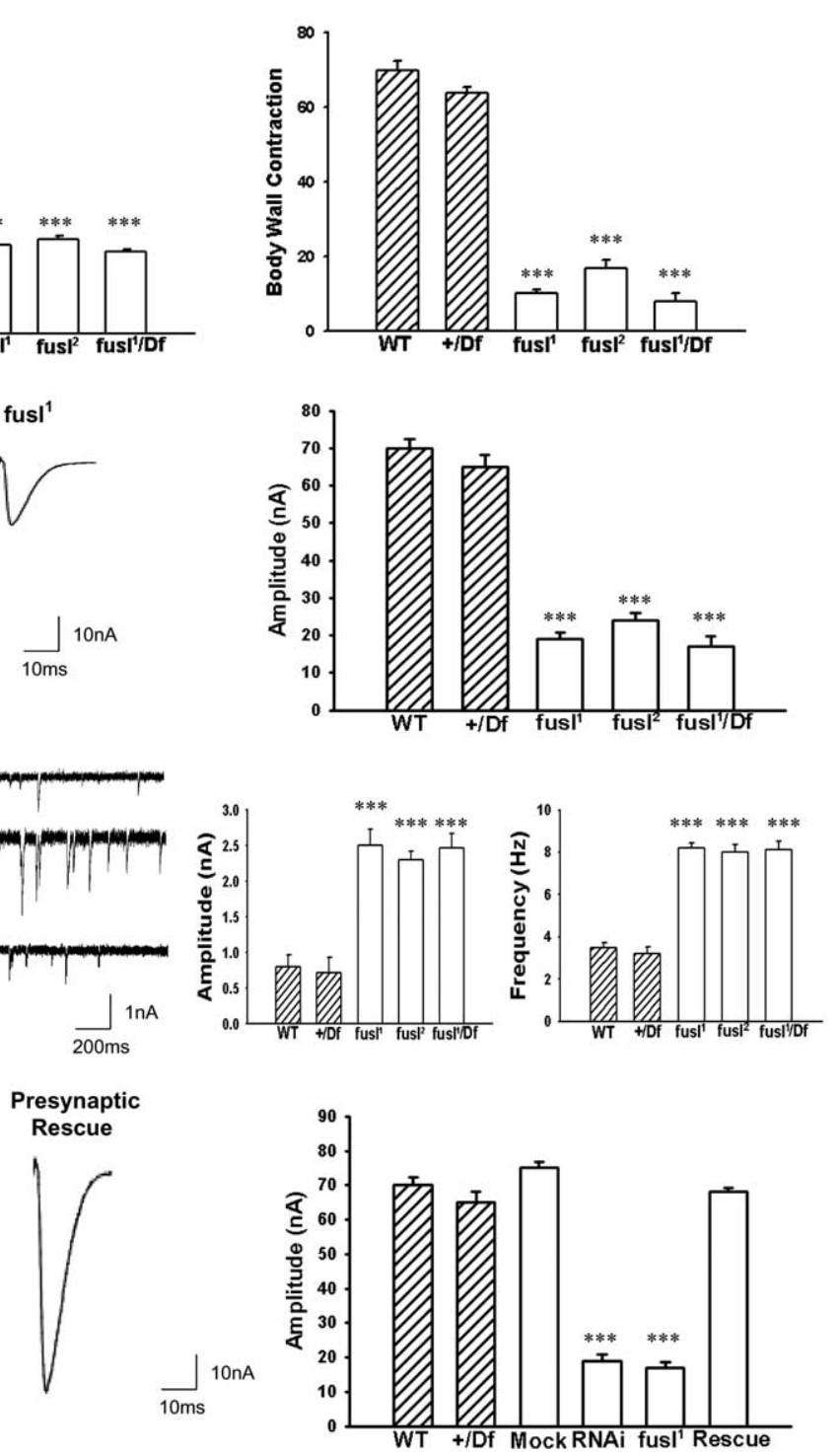

Figure 5. Loss of Fusl critical impairs movement and NMJ synaptic function. $\boldsymbol{A}$, Defective larval movement in fus/ mutants. Movements were quantified over a 1 min period for both pharynx contraction (left) and body wall peristalsis (right). All fus mutants (open bars) display significantly reduced movements compared with both controls (hatched bars). $p<0.001 ; N=10$ animals for all genotypes shown. $\boldsymbol{B}$, Impaired NMJ synaptic transmission in fus/ mutants. Representative traces of EJCs (left), evoked by $0.5 \mathrm{~Hz}$ motor nerve stimulation in control and fus/ mutant. Current recordings were made in TEVC mode at $-60 \mathrm{mV}$ from muscle 6 (segment 3). Right, Quantified mean EJ (amplitude for controls (hatched bars) and mutants (open bars). $p<0.001$; $N=10$ animals for each genotype. C, Mutants display increased spontaneous neurotransmission events. Representative mEJCs (left) traces in control (top), mutant (middle), and mutant with one copy of wild-type fus/ transgene (bottom). The fus/ mutant displays a higher frequency of $m E J C s$ with obviously elevated amplitudes. Quantification of $m E J C s$ reveals a threefold increase in mean mEJC amplitude (left) and more than twofold increase in mean mEJC frequency (right). $p<0.001 ; N=10$ animals for all genotypes. D, RNAi knockdown of CG14021 mimics the fus/mutant transmission defect, and targeted presynaptic expression of a wild-type CG14021 transgene rescues the fus/ mutant transmission defect. Representative EJC traces (left) from WT control, dsRNAi injected animal, and presynaptic transgenic rescue of fus/ mutant (elav-GAL4; UAS-CG14021 in the fusl ${ }^{1} /$ fusl $^{1}$ background). Right, Quantification of mean EJC amplitude in controls (hatched bars), mock and dsRNAi injected animals, fus/ mutant alone and with transgenic (G14021 rescue. Sample size of 10 animals for all genotypes represented ( $p<0.001$ ). Error bars indicate SEM.

with controls. The homozygous fusl $l^{1}$ and fusl ${ }^{2}$ mutants, and the heterozygous fusl ${ }^{1} / \mathrm{Df}$ mutants, all exhibit a highly significant reduction in pharyngeal movements and locomotor body wall contractions $(p<0.001 ; N=10$ animals for each genotype), compared with both wild-type (WT) and +/Df controls (Fig. 5A). Similar behavioral defects have been described as defining a synaptic impairment (Xing et al., 2005).
To directly assess synaptic function of the larval NMJ, basal neurotransmission assays were done on fuseless mutants and controls, with both evoked EJCs and spontaneous miniature EJCs (mEJCs) measured in the TEVC configuration (Fig. $5 B, C)$. Evoked transmission assays were done in $0.5 \mathrm{~mm}$ extracellular $\left[\mathrm{Ca}^{2+}\right]$, to reveal changes in basal synaptic function most clearly (Rohrbough et al., 1999; Zhang et al., 2001; Trotta et al., 2004). At a stimulation frequency of $0.5 \mathrm{~Hz}$, control animals exhibited a mean EJC amplitude of $69.5 \pm 4.9 \mathrm{nA}$, whereas all fusl mutants showed a similar, highly significant decrease in EJC amplitude: $19.1 \pm 3.5 \mathrm{nA}$ $\left(\right.$ fusl $\left.^{1}\right), 21.3 \pm 3.9 \mathrm{nA}\left(\right.$ fusl $\left.^{2}\right)$, and $18.2 \pm$ $4.0 \mathrm{nA}\left(\right.$ fusl $\left.^{1} / \mathrm{Df}\right)(p<0.001 ; N=12$ for all genotypes) (Fig. 5B). These results show that Fusl plays an important facilitatory function in synaptic transmission.

To assay spontaneous vesicle fusion in the absence of evoked synaptic transmission, $\mathrm{mEJCs}$ were recorded in the presence of TTX in the same $0.5 \mathrm{~mm}\left[\mathrm{Ca}^{2+}\right]$. Surprisingly, all fusl mutants showed a significant increase in both the amplitude and frequency of mEJC fusion events (Fig. $5 C$, sample traces at left). The mEJC amplitude was elevated nearly threefold in the absence of fusl function; in controls, $\mathrm{mEJC}$ amplitude was $0.7 \pm 0.4 \mathrm{nA}$ (WT) and $0.6 \pm 0.2 \mathrm{nA}(+/ \mathrm{Df})$, whereas in mutants mEJC amplitude was $2.5 \pm 0.4 \mathrm{nA}\left(\right.$ fusl $\left.^{1}\right)$, $2.3 \pm 0.3 \mathrm{nA}\left(\right.$ fusl $\left.^{2}\right)$, and $2.46 \pm 0.21$ $\left(\right.$ fusl $\left.^{1} / \mathrm{Df}\right)(p<0.001 ; N=10$ animals for all genotypes) (Fig. 5C, middle). The mEJC frequency was more than doubled in the absence of fusl function; in controls, mEJC frequency was $3.6 \pm 0.5 \mathrm{~Hz}(\mathrm{WT})$ and $3.2 \pm 0.6 \mathrm{~Hz}(+/ \mathrm{Df})$, whereas in mutants mEJC frequency was $8.2 \pm 0.23$ $\left(f u s l^{l}\right), 7.9 \pm 0.36\left(\right.$ fusl $\left.^{2}\right)$, and $8.0 \pm 0.43$ ( fusl $\left.{ }^{1} / \mathrm{Df}\right)(p<0.001 ; N=10$ animals for all genotypes) (Fig. $5 C$, right). These data show that loss of fusl function dramatically reduces evoked neurotransmission efficacy, while increasing the size and rate of spontaneous synaptic vesicle fusion events.

The similarity in fusl $^{l}$, fusl ${ }^{2}$, and fusl $l^{l} / \mathrm{Df}$ quantified phenotypes suggest that both fusl ${ }^{1}$ and fusl ${ }^{2}$ represent the null mutant condition, consistent with the sequenced stop mutations in CG14021 (Fig. 2B). RNAi against CG14021 and transgenic expression of the wild-type CG14021 gene were additionally used to confirm the fusl gene identity (Fig. $5 D$ ). When EJC amplitudes were measured, as above, CG14021 RNAi injected animals had a similar phenotype to fusl $^{l}$ mutants: $17.4 \pm 1.57 \mathrm{nA}$ $\left(\right.$ fusl $l^{l}$ ) compared with $19.2 \pm 1.89 \mathrm{nA}$ (RNAi) $(p<0.001$ to WT; $N=10$ animals for both genotypes). As a control, mock-injected animals had robust EJCs, indistinguishable from WT (Fig. 5D, 
right). A wild-type copy of UAS-CG14021 driven by the neuronal GAL4-elav in the fusl $^{l}$ homozygous null mutant background completely rescued the synaptic transmission defect (Fig. 5D, "rescue" sample trace on the left). The transgenic rescue animals showed average EJC amplitudes of $66.1 \pm 1.0 \mathrm{nA}$, comparable with the controls (Fig. 5D, right). The elevated mEJC amplitude and frequency were similarly rescued on presynaptic expression of the wild-type fusl transgene (Fig. 5C, bottom trace). Controls showed average mEJC amplitude of $0.62 \pm 0.3 \mathrm{nA}$ and frequency of $3.4 \pm 0.7 \mathrm{~Hz}$, and fusl mutants with one copy of the wild-type gene expressed presynaptically displayed a similar $0.7 \pm 0.4 \mathrm{nA}$ amplitude and $3.9 \pm 0.9 \mathrm{~Hz}$ amplitude $(p>0.05 ; N=10$ animals for both genotypes). Note that full rescue of evoked and spontaneous transmission is achieved by driving the fusl gene only in the presynaptic cell. Thus, these data confirm the fusl gene identity and also demonstrate a specific presynaptic requirement for the Fusl protein.

\section{Fuseless regulates the synaptic vesicle} cycle and vesicle exocytosis

Fuseless in the presynaptic membrane regulates neurotransmission efficacy, predicting defective neurotransmitter release. To investigate the size and cycling dynamics of the endo-exo SV pool, the lipophilic fluorescent dye FM1-43 was used to image endocytosis and exocytosis (Fig. 6) (Kuromi and Kidokoro, 2000; Fergestad and Broadie, 2001; Trotta et al., 2004). Larval NMJ preparations were exposed to FM1-43 in the presence of $90 \mathrm{~mm}\left[\mathrm{~K}^{+}\right]$saline, which depolarizes the nerve terminal and induces rapid vesicular cycling. Preparations were then washed and imaged in buffered $0 \mathrm{~mm}\left[\mathrm{Ca}^{2+}\right]$ saline to halt SV cycling. A second high $\left[\mathrm{K}^{+}\right]$depolarization was used in the absence of FM1-43 to assess dye unloading by SV exocytosis. Representative images of loaded and unloaded NMJ arbors are shown in Figure 5A. Mean fluorescent intensities were quantified after both FM1-43 loading and unloading. After loading, control boutons displayed mean fluorescent values of $172.1 \pm 5.9(\mathrm{WT})$ and $165.3 \pm 5.3(+/ \mathrm{Df})$, whereas fusl mutants showed significantly reduced loading; $122 \pm 5.2\left(\right.$ fusl $\left.^{1}\right), 112.1 \pm$ $4.8\left(\right.$ fusl $\left.^{2}\right)$, and $115.0 \pm 5.7\left(\right.$ fusl $\left.^{l} / \mathrm{Df}\right)(p<0.01 ; N=10$ animals for each genotype) (Fig. $6 \mathrm{~B}$, left "load"). This phenotype indicates a decrease in the cycling rate or size of the exo-endo SV pool, consistent with presynaptic impairment of neurotransmission (Kuromi and Kidokoro, 2000). After unloading, controls displayed a reduction of FM1-43 fluorescence of $>90 \%$, whereas the fusl mutants showed a high FM1-43 dye retention and a specifically compromised ability to unload (Fig. 6A). The mean values after unloading for the controls was $15.4 \pm 4.6$ (WT) and $19.3 \pm$ 5.7 (+/Df), whereas the mutants showed more than fivefold higher values of $114.0 \pm 5.6\left(\mathrm{fusl}^{1}\right), 103.1 \pm 4.7\left(\mathrm{fusl}^{2}\right)$, and $109.2 \pm 5.7$ ( fusl $l^{1}$ Df $)(p<0.001 ; N=10$ animals for all genotypes) (Fig. $6 \mathrm{~B}$, right "unload"). These data indicate that SV cy- cling is impaired in fusl mutants, with a particularly severe defect in SV exocytosis.

To examine synaptic vesicles directly, we used electron microscopy to quantify SV number and distribution within presynaptic boutons (Fig. 7). The overall synaptic ultrastructure appeared normal in fusl null mutants (Fig. 7A). Presynaptic boutons were of normal size, contained the expected array of organelles, and displayed well differentiated presynaptic and postsynaptic membrane profiles. Controls had bouton areas of $4.9 \pm 0.6(\mathrm{WT})$ and $3.7 \pm 0.4(+/ \mathrm{Df})$, whereas mutants had areas of $3.9 \pm 0.4\left(\mathrm{fusl}^{1}\right)$ and $4.7 \pm 0.5\left(\mathrm{fusl}^{1} / \mathrm{Df}\right)(p>0.4 ; N=4$ animals, $>20$ boutons for each genotype). Likewise, presynaptic active zones appeared well differentiated, with a normal ultrastructural appearance (Fig. 7B). Synaptic vesicles appeared the same size in mutant and controls. In contrast, loss of Fusl results in striking differences from control in SV populations, with a dramatic elevation of vesicle number throughout the bouton (Fig. 7A) and specifically clustered around presynaptic active zones (Fig. $7 B$ ). In fusl mutants, the SV number was more than doubled as quantified by counting the number of total vesicles in each NMJ profile; the SV number in controls was $199 \pm 19.0$ (WT; $N=21$ ) and 184.5 \pm 27.1 ( $+/ \mathrm{Df} ; N=20)$, whereas the SV number in mutants was $422 \pm 53.4\left(\right.$ fusl $\left.^{1} ; N=17\right)$ and $475 \pm$ 69.4 ( uss $\left.^{l} / \mathrm{Df} ; N=16\right)(p<0.001)$ (Fig. 6C). In terms of vesicle 


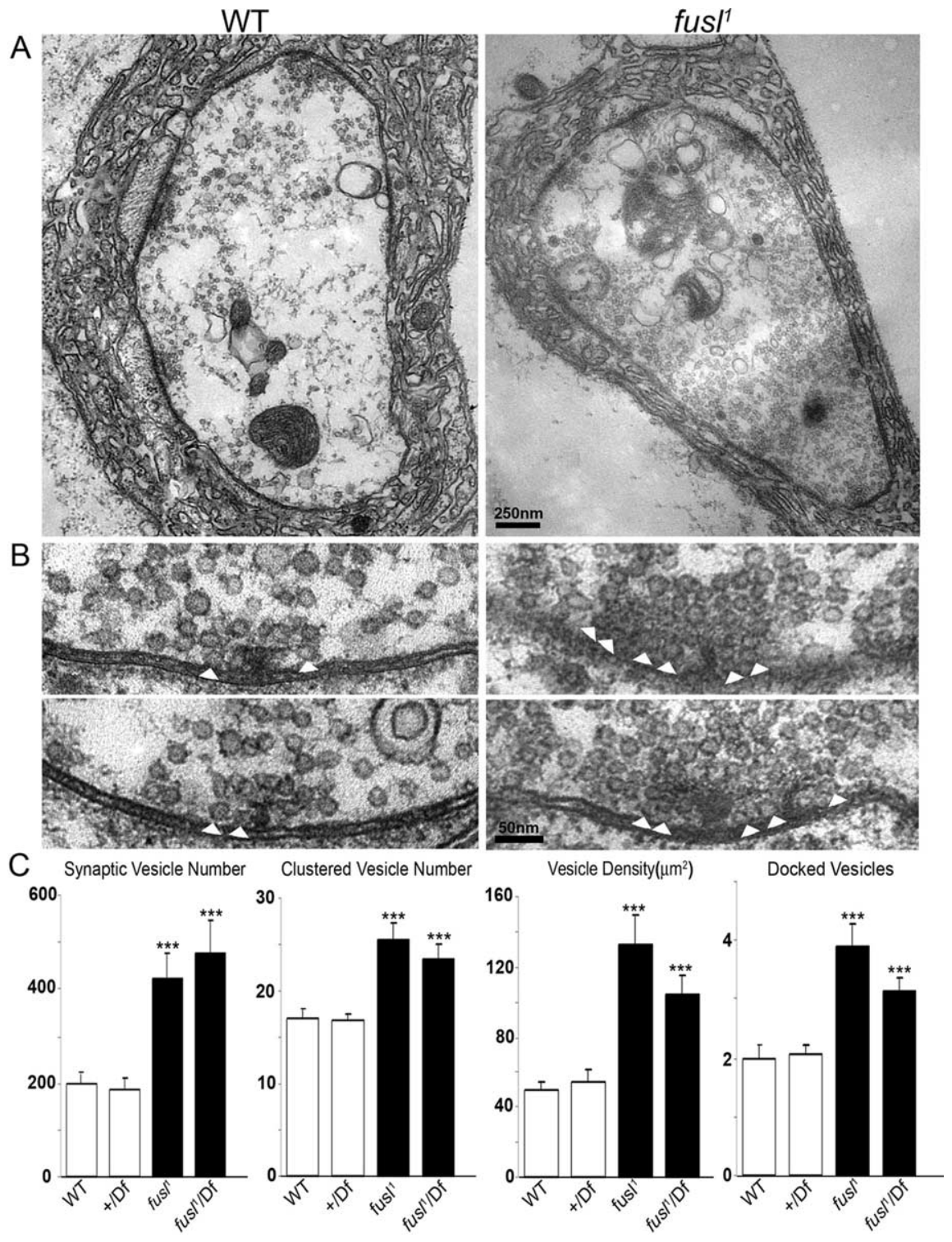

Figure 7. Ultrastructural analyses reveal accumulation of clustered and docked synaptic vesicles at presynaptic active zones in fus/ mutant. $\boldsymbol{A}$, Representative TEM images of WT control (left) and fus/ mutant (right) NMJ boutons. The mutant has normal bouton size, morphology, and postsynaptic subsynaptic reticulum. Normal active zones are visible in both panels as electrondense synaptic membranes and T-bars. Null fus/mutant synapses display an obvious increase of synaptic vesicles throughout the terminal. Scale bar, $250 \mathrm{~nm}$. B , High magnification images of active zones. In control animals (left), the clustered area (250 nm radius from T-bar center) has $\sim 15$ vesicles localized around the T-bar and $\sim 2$ docked vesicles (white arrowheads) contacting the presynaptic plasma membrane adjacent to the T-bar. In fus/mutants (right), there is a dense aggregation of clustered vesicles and clear increase in the number of docked vesicles. Scale bar, $50 \mathrm{~nm}$. C, Quantitative analysis of ultrastructural phenotypes, including total vesicle number, clustered vesicle number ( $<250 \mathrm{~nm}$ from T-bar), vesicle density, and docked vesicle number $(<20 \mathrm{~nm}$ from AZ). The white bars represent control animals, and the black bars represent mutant animals. The bouton profile sample size is $>17$ for each parameter; four animals were assayed for each genotype. Significance is indicated as follows: ${ }^{* * *} p<0.001$. Error bars indicate SEM.

density (in square micrometers), the numbers were $49.6 \pm 4.5$ (WT) and 54.9 \pm 6.9 (+/Df) for controls, and more than doubled density in mutants at $132 \pm 16.9\left(\right.$ fusl $\left.^{l}\right)$ and $103 \pm 10.8\left(\right.$ fusl $^{l} /$ Df). There was a parallel increase in the number of synaptic vesicles clustered ( $<250 \mathrm{~nm}$ ) around individual active zones; in controls, the clustered SV number was $17.0 \pm 0.9(\mathrm{WT} ; N=21)$ and $16.8 \pm 0.8(+/ \mathrm{Df} ; N=20)$, whereas in mutants it was $25.5 \pm 1.6$ ( fusl $\left.^{l} ; N=17\right)$ and $23.4 \pm 1.4\left(\right.$ fusl $\left.^{l} / \mathrm{Df} ; N=20\right)(p<0.001)$ (Fig. 7C). Likewise, the number of SVs physically docked at the presynaptic active zone densities was very significantly increased in fusl mutants. In controls, the number of docked vesicles was $2.0 \pm 0.2(\mathrm{WT} ; N=$ $21)$ and $2.0 \pm 0.1(+/ \mathrm{Df} ; N=20)$, and it increased in mutants to $3.8 \pm 0.4$ ( fusl $^{1}$; $N=17)$ and $3.1 \pm 0.2\left(\right.$ fusl $\left.^{1} / \mathrm{Df} ; N=20\right)$. These defects are characteristic in known SV fusion mutants (Richmond and Broadie, 2002; Kidokoro, 2003; Huang et al. 2006) and indicative of an impairment in SV exocytosis.

\section{Loss of Fusl causes $\left[\mathrm{Ca}^{2+}\right]$ insensitivity during neurotransmission}

To further examine the cause of $\mathrm{Ca}^{2+}$. dependent transmission impairments in the absence of fuseless, we assayed the effect of external $\left[\mathrm{Ca}^{2+}\right]$ on transmission amplitude (Fig. 8). Stimulation-evoked EJCs were compared over a range of $\left[\mathrm{Ca}^{2+}\right]$ from 0.2 to $1.8 \mathrm{~mm}$. Figure $7 \mathrm{~A}$ shows sample traces of wild-type controls and fusl $^{l}$ mutants at $0.2,0.4$, and $1.0 \mathrm{~mm}$ $\left[\mathrm{Ca}^{2+}\right]$. At the low end of this range $(0.2$ $\left.\mathrm{mm}\left[\mathrm{Ca}^{2+}\right]\right)$, fusl mutants display a mean EJC amplitude of $7.2 \pm 5.4 \mathrm{nA}$ compared with control amplitude of $11.1 \pm 4.6 \mathrm{nA}$ (Fig. 8A). At the higher end $(1.0 \mathrm{~mm}$ $\left.\left[\mathrm{Ca}^{2+}\right]\right)$, fusl mutants had a mean EJC amplitude of $18.7 \pm 4.2 \mathrm{nA}\left(\right.$ fusl $\left.^{1}\right)$ compared with $110 \pm 4.9 \mathrm{nA}$ in control (Fig. $8 A$ ). Thus, over this $\left[\mathrm{Ca}^{2+}\right]$ range, the amplitude of the control EJC increased 10-fold, whereas the mutant increased only 2 -fold. These data suggest an impairment in the $\mathrm{Ca}^{2+}$ influx trigger driving synaptic vesicle exocytosis.

EJC amplitudes are graphed as a function of external $\left[\mathrm{Ca}^{2+}\right]$ in Figure $8 B$. In lower external calcium $(<1.0 \mathrm{~mm})$, $\left[\mathrm{Ca}^{2+}\right]$ primarily limits EJC transmission and a sharp rise in EJC amplitudes occurs in the control compared with fusl mutants. At higher $\left[\mathrm{Ca}^{2+}\right](>1.0 \mathrm{~mm})$, transmission strength is no longer solely limited by $\left[\mathrm{Ca}^{2+}\right]$, but mean EJC amplitude in controls continues to increase with increasing $\left[\mathrm{Ca}^{2+}\right]$ (Fig. $8 \mathrm{~B}$ ). In contrast, in fusl mutants there is very little $\mathrm{Ca}^{2+}$-dependent increase in EJC amplitude as a function of increasing external $\left[\mathrm{Ca}^{2+}\right]$ (Fig. $8 \mathrm{~B}$ ). These data indicate a remarkable reduction in the sensitivity of basal neurotransmission strength to external $\left[\mathrm{Ca}^{2+}\right]$ in the absence of Fusl function. Given the presynaptic membrane localization of the Fusl protein, these functional defects are most consistent with impaired $\mathrm{Ca}^{2+}$ influx.

Presynaptic calcium channel localization depends on Fuseless One explanation for the functional defects in fusl mutants could be loss or functional misregulation of presynaptic $\mathrm{Ca}^{2+}$ channels. The Drosophila NMJ contains a single, well characterized voltagegated $\mathrm{Ca}^{2+}$ channel, with the pore-forming $\alpha 1$ subunit encoded by cacophony (cac) (Von Schilcher, 1976; Kawasaki et al., 2000, 

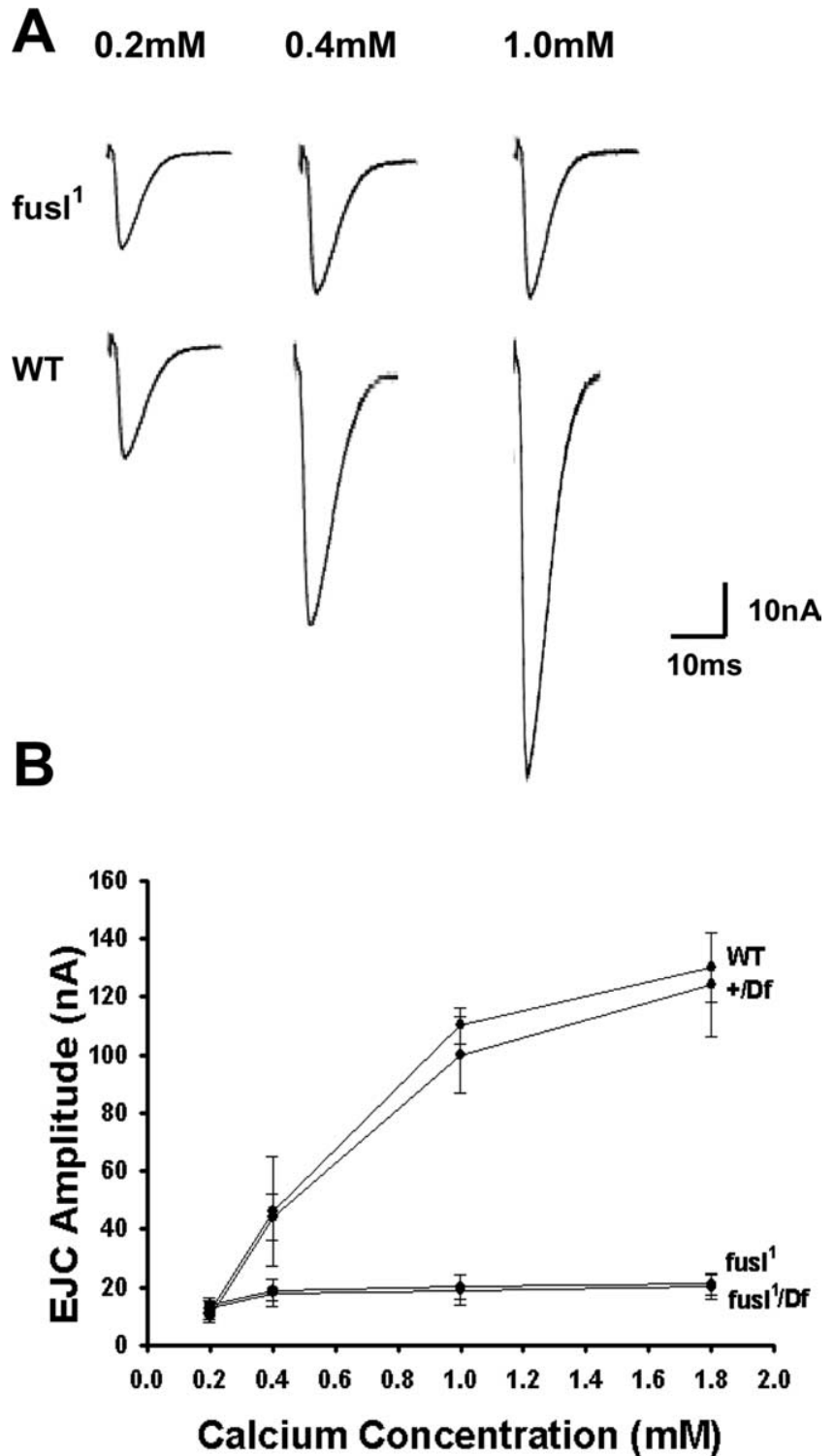

Figure 8. Loss of the $\mathrm{Ca}^{2+}$ sensitivity of neurotransmission. $A$, Representative EJC records from fus mutants (top row) and WT controls (bottom row) in a range of external $\left[\mathrm{Ca}^{2+}\right]$ as follows: $0.2 \mathrm{~mm}$ (left), $0.5 \mathrm{~mm}$ (center), and $1.0 \mathrm{~mm}$ (right). Null fus/mutants display insensitivity to increasing $\left[\mathrm{Ca}^{2+}\right]$, with only small increases in EJC amplitude. B, Quantification of EJC amplitude as a function of $\left[\mathrm{Ca}^{2+}\right]$. Mean EJC amplitudes are shown for $0.2,0.4,1.0$, and $1.8 \mathrm{~mm}$ $\left[\mathrm{Ca}^{2+}\right]$ for two controls (WT, Df/+) and two mutants ( fusl $l^{1}$, fus $l^{1}$ Dff). Sample size: 10 animals per genotype for each data point. Error bars indicate SEM.

2004; Xing et al., 2005). To examine these calcium channels, we used a UAS-Cac-GFP fusion protein driven with presynaptic elav-GAL4, which has previously been used to document the tight, punctate localization of Cacophony $\mathrm{Ca}^{2+}$ channels at presynaptic active zones (Kawasaki et al., 2004). This transgenic reporter was crossed into the control and fusl $^{1}$ null backgrounds, with Cac-GFP expression analyzed using confocal microscopy (Fig. 9).

In agreement with previous reports, we found that Cac-GFP localizes to a number of discrete punctate active zone domains in presynaptic NMJ boutons (Fig. 9A). In striking contrast, CacGFP is dramatically reduced in fusl mutants; the overall expression level is much lower and the punctate Cac-GFP domains are only barely distinguishable (Fig. 9A, right). These $\mathrm{Ca}^{2+}$ channels were quantified by counting the number of Cac-GFP puncta per
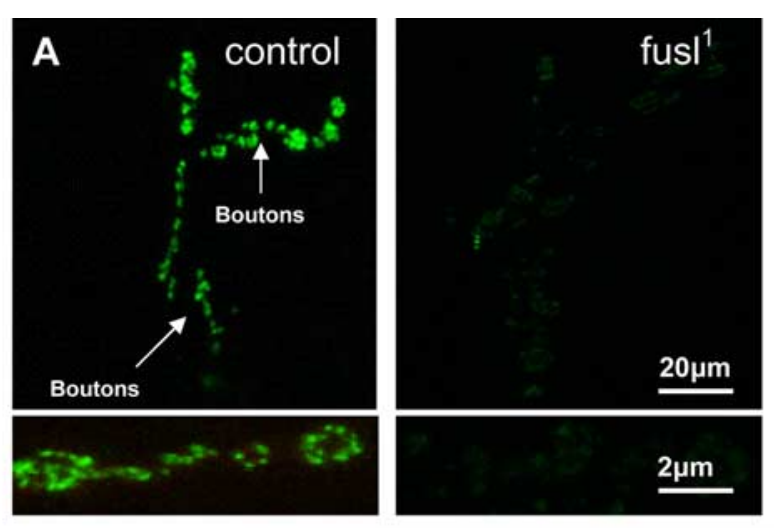

B
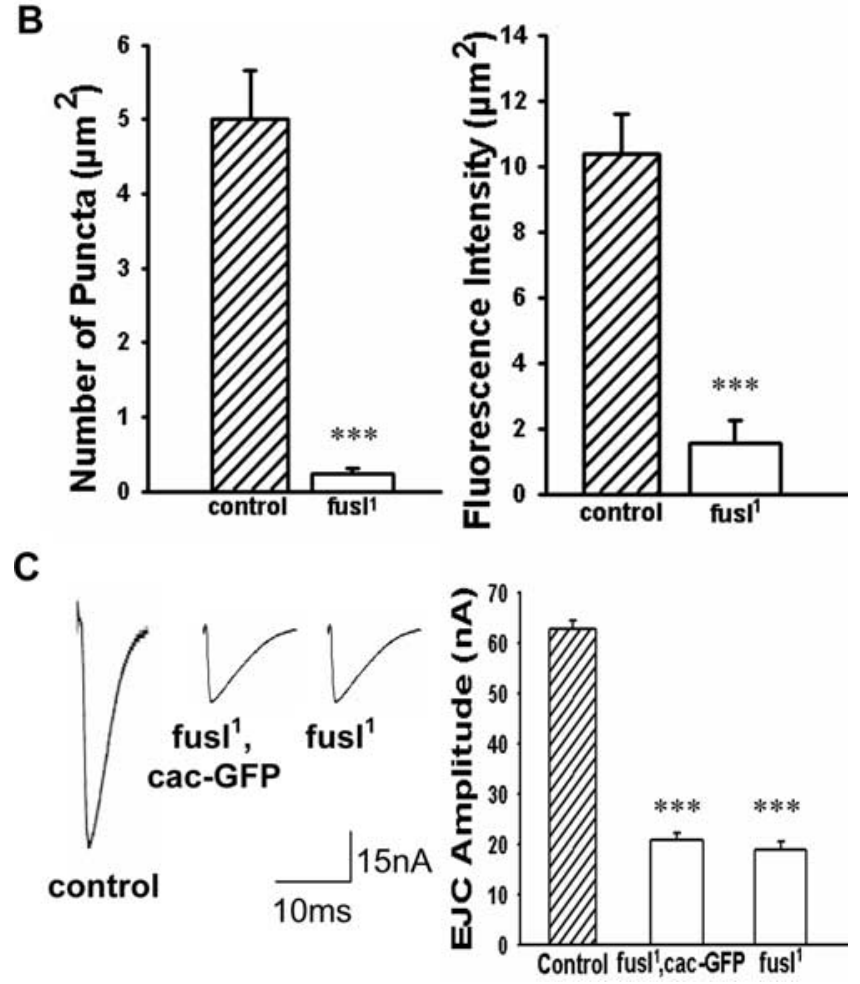

Figure 9. Presynaptic voltage-gated $\mathrm{Ca}^{2+}$ channels lost in fus/ mutants. A transgenic line of the Cacophony $\alpha-1$ pore subunit of the presynaptic voltage-gated $\mathrm{Ca}^{2+}$ channel fused to GFP (UAS-Cac-GFP) driven by the elav-GAL4 neural driver in the presynaptic NMJ terminal in the control or fus $\left.\right|^{7}$ null backgrounds. A, Representative images of control (left) and fusl ${ }^{7}$ mutant (right) expressing (ac-GFP. Low magnification images of the NMJ (top) and high magnification images of synaptic boutons (bottom). Scale bars: Top, $20 \mu \mathrm{m}$; bottom, $2 \mu \mathrm{m}$. B, Quantitation of the number of Cac-GFP puncta (left) and the Cac-GFP fluorescent intensity density (right). Control and mutant are very highly significantly different $\left.{ }^{* * *} p<0.0001\right)$. C, Representative EJC traces of elav-GAL4; UAS-Cac-GFP in a wild-type background (control), a fus ${ }^{1}$ homozygous background ( fus $I^{1}$, Cac-GFP), and the fus $l^{1}$ mutant alone ( fus $l^{1}$ ). Right, Quantification of mean EJC amplitudes. There was no significant difference between fusl ${ }^{1}$, Cac-GFP, and fus ${ }^{1}$ mutants, but there was a significant $p<0.0001$ difference between mutants and control. $N=10$ animals for each genotype. Error bars indicate SEM.

bouton and by calculating the mean density (Fig. $8 \mathrm{~B}$, left), as well as by measuring the fluorescence intensity throughout synaptic boutons and calculating the mean intensity per unit area (Fig. 9B, right). The number of Cac-GFP puncta in fusl mutants is very significantly $(p<0.0001 ; N=10$ animals, 20 NMJs and 100 boutons per genotype) reduced compared with control (control, $4.9 \pm 2.4$; fusl ${ }^{l}, 0.3 \pm 0.1$ ) (Fig. 9B). In most boutons within a mutant NMJ arbor, there were no detectable $\mathrm{Ca}^{2+}$ channel domains and those observed were very faint. Because this assay 
method is somewhat subjective, the mean fluorescence intensity of Cac-GFP was next assessed by outlining synaptic boutons and measuring the average density of the fluorescent signal in controls and mutants. Control synaptic terminals had a mean CacGFP density of $10.4 \pm 3.4$, whereas fusl null terminals had a 10 -fold lower density of $1.7 \pm 0.9$ ( fusl $l^{l}$ ) (Fig. $9 B$, right) $(p>$ 0.0001; $N=10$ animals, 20 NMJs and 100 boutons per genotype). These results show that Fusl plays a critical role in the localized expression of the Cacophony voltage-gated $\mathrm{Ca}^{2+}$ channels in presynaptic boutons and specifically in the formation of active zone domains.

Driving UAS-Cac-GFP in neurons represents an overexpression condition, with terminals containing the native Cacophony voltage-gated $\mathrm{Ca}^{2+}$ channels as well as the introduced fusion protein, which is known to be functional (Kawasaki et al., 2004). Because fusl mutants show a defect in $\mathrm{Ca}^{2+}$ channel expression (Fig. $8 \mathrm{~A}$ ), this overexpression condition could provide some rescue of the neurotransmission phenotype. To test this possibility, electrophysiology was used to compare basal EJC amplitudes in the control and experimental lines. Representative traces (left) and the quantified mean EJC amplitudes (right) are shown in Figure 9C. Overexpression of the Cacophony $\mathrm{Ca}^{2+}$ channel was unable to detectably rescue the fuseless evoked transmission defect (control, $62.1 \pm 4.2 \mathrm{nA}$; fusl $^{1}, 18.6 \pm 3.2 \mathrm{nA}$; fusl ${ }^{1}$, Cac-GFP, $20.2 \pm 3.9 \mathrm{nA})$ (Fig. 9C) $(p<0.0001$ between mutants and control; $N=10$ animals per genotype). These data show that Fusl is required for presynaptic localization of voltage-gated $\mathrm{Ca}^{2+}$ channels.

\section{Discussion}

Using an unbiased, forward genetic screen for synaptic dysfunction mutants in the Drosophila visual system, we identified a new presynaptic integral membrane protein with a critical function in regulating active zone voltage-gated $\mathrm{Ca}^{2+}$ channels and thus the $\mathrm{Ca}^{2+}$ trigger driving the synaptic vesicle fusion underlying neurotransmission. The Fuseless protein is a predicted eight-pass transmembrane protein whose closest known human homolog is the transmembrane protein Sialin, a transporter belonging to a group of anion/cation symporters (Wreden et al., 2005; Yarovaya et al., 2005). The monosaccharide sialic acid cleaved from sialoglycoconguates is exported across membranes by the Sialin transporter (Morin et al., 2004). Two inherited diseases occur when the sialin gene is mutated: infantile sialic acid storage disease and Salla disease, which are characterized by severe CNS defects including mental retardation (Verheijen et al., 1999; Morin et al., 2004). The modification of cell surface proteins by addition of sialic acid is known to regulate critical neuronal processes including intercellular adhesion and signaling (Kiss and Rougon, 1997). In Drosophila, fuseless mutations profoundly disrupt synaptic transmission, both at central, histaminergic photoreceptor synapses and at peripheral, glutamatergic NMJ synapses, indicating a conserved, critical function in multiple classes of chemical synapse. The requirement for the Fusl protein can be supplied with expression targeted only to the presynaptic side, indicating a function in transmitter release. Functional defects in fusl mutants are similar to those found in the $\mathrm{Ca}^{2+}$ channel mutant cacophony (Kawasaki et al., 2000; Xing et al., 2005). Other mechanistic defects also suggest a disrupted $\mathrm{Ca}^{2+}$-trigger for exocytosis, including reduced FM1-43 and SV cycling. Consistently, the Fusl protein strongly regulates Cacophony $\mathrm{Ca}^{2+}$ channel localization to presynaptic active zones. Together, these results indicate that formation of active zone $\mathrm{Ca}^{2+}$ channel domains is the primary role of Fuseless in controlling neurotransmission strength.

\section{Fuseless regulates neurotransmitter release to control transmission strength}

Loss of Fuseless protein results in a range of synaptic dysfunction phenotypes that appear to be mechanistically linked to disruption of presynaptic $\mathrm{Ca}^{2+}$ dynamics. Mutant synapses display a strong reduction in evoked neurotransmitter release over a wide range of external calcium concentrations. In low $\left[\mathrm{Ca}^{2+}\right]$, normal synapses display a log-linear dependence of transmitter release on $\left[\mathrm{Ca}^{2+}\right]$ (Dodge and Rahamimoff, 1967), but fusl null synapses display only a small increase in transmission amplitude even with large changes in external $\left[\mathrm{Ca}^{2+}\right]$, indicating a fundamental defect in $\mathrm{Ca}^{2+}$ influx dependent secretion (Zucker, 1993, 1996). In contrast, fusl mutants exhibit elevated spontaneous vesicle fusion frequency and amplitude, which are both rescued by targeted presynaptic expression of the wild-type fusl gene, indicating elevated secretion under nonstimulated conditions (Deitcher et al., 1998; Yoshihara et al., 2000; Trotta et al., 2004). The increased mEJC amplitude may reflect an increased incidence of synchronous spontaneous fusion events, although summation events are evident in only a small subset of currents. It appears unlikely that either increased SV glutamate content (Daniels et al., 2004) or compensatory upregulation in postsynaptic glutamate receptor density (DiAntonio et al., 1999) are involved, because vesicle size appears normal in ultrastructural studies and glutamate receptor expression/function are not detectably altered in fusl null mutants. The increased incidence of spontaneous vesicle fusion events is consistent the elevated number of vesicles docked at presynaptic active zones. It is widely believed that fusion probability is a function, in part, of the number of docked, fusioncompetent vesicles.

\section{Fuseless regulates presynaptic active zone calcium channel domains}

The calcium concentration in the nerve terminal at rest is astoundingly low, providing the necessary canvas for the action potential-driven spike of calcium influx to drive rapid vesicle exocytosis (Katz and Miledi, 1968, 1970; Llinas et al., 1976). The Fuseless protein plays a critical role in the presynaptic localization of voltage-gated $\mathrm{Ca}^{2+}$ channels, as revealed by assaying the cacophony-encoded $\alpha 1$ pore subunit, which directly mediates $\mathrm{Ca}^{2+}$ influx. In mammals, the binding of the target soluble $N$-ethylmaleimide-sensitive factor attachment protein receptor (tSNARE) Syntaxin to presynaptic $\mathrm{Ca}^{2+}$ channels led to the identification of the SYNPRINT interaction domain within P/Q and $\mathrm{N}$ type channel subunits (Sheng et al., 1998). The SYNPRINT domain is thought to physically tether the $\mathrm{Ca}^{2+}$ channel to Syntaxin to help mediate the localized, rapid coupling of $\mathrm{Ca}^{2+}$ influx to vesicle fusion (Mochida et al., 1996; Sheng et al., 1998), and also bidirectionally regulate the activity of the channels (Wu et al., 1999). In Drosophila, the cacophony $\mathrm{Ca}^{2+}$ channel triggers similar fast neurotransmitter release (Kawasaki et al., 2000), but no sequence homologous to SYNPRINT has been identified (Wu et al., 1999; Littleton and Ganetzky, 2000), suggesting another mechanism for coupling $\mathrm{Ca}^{2+}$ influx to the fusion of docked vesicles (Kawasaki et al., 2002). In vertebrates, the calcium channel $\alpha 1$ subunit has been demonstrated to regulate channel dynamics including activation/inactivation rates, and also directly interacts with Synaptotagmin and other proteins involved in $\mathrm{Ca}^{2+}$ dependent vesicle fusion (Hille, 2001). Interestingly, the $\alpha 1$ subunit has also been demonstrated to bind extracellular laminins, and facilitate the organization of presynaptic active zones (Nishimune et al., 2004). It follows, then, that significant loss of the $\alpha 1$ subunit predicts underdeveloped active zones and significant re- 
duction in transmitter exocytosis (Kittel et al., 2006; Wagh et al., 2006).

In all characterized synapses, calcium channels cluster at presynaptic active zones, where they form a tight spatial association with synaptic vesicles docked and ready for fusion (Mochida et al., 1996; Sheng et al., 1998; Wu et al., 1999; Nishimune et al., 2004). In the absence of Fusl protein, ultrastructurally normal active zones form, but fail to cluster $\mathrm{Ca}^{2+}$ channels. It has been recently reported that reduction in $\mathrm{Ca}^{2+}$ channel density or function can contribute to disorganized active zones (Nishimune et al., 2004; Kittel et al., 2006; Wagh et al., 2006) and a reduction in active zone formation (Kittel et al., 2006; Wagh et al., 2006). In particular, it has been proposed that the Drosophila Bruchpilot protein stabilizes the formation of active zones by triggering the integration of active zone components and specifically Cacophony $\mathrm{Ca}^{2+}$ channels. The bruchpilot mutants show reduced $\mathrm{Ca}^{2+}$ channel clustering, density, and localization, and reduced vesicular release probability (Kittel et al., 2006; Wagh et al., 2006). Likewise, in fuseless mutants, loss of $\mathrm{Ca}^{2+}$ channels, and $\mathrm{Ca}^{2+}$ channel local function, is proposed to be the primary defect in coupling $\mathrm{Ca}^{2+}$ influx to vesicle exocytosis, leading to the observed disruption in vesicle release probability.

Null fuseless mutants have an increased number of vesicles clustered and docked at the presynaptic density. These phenotypes are consistent with direct disruption of $\mathrm{Ca}^{2+}$-triggered vesicle exocytosis. Similar vesicle accumulation characterizes syntaxin1A, dunc-13, comatose, and rolling blackout mutants, for example, each of which has a specific exocytosis deficit (Broadie et al., 1995; Kawasaki et al., 1998; Littleton et al., 1998; Aravamudan et al., 1999; Kidokoro, 2003; Huang et al., 2006). It has been shown that a specific block in SV exocytosis leads to a secondary accumulation of vesicles in pools upstream of the presynaptic membrane. FM dye studies complement the ultrastructural analyses. As is expected for any defect in the SV cycle, there is a decrease in the overall rate of endo-exo cycling in fusl mutants. In addition, there is a particularly severe defect in acute FM dye release in the absence of Fusl function, consistent with a specific defect in SV exocytosis. We attribute these fusl mutant defects wholly to the loss of the appropriate $\mathrm{Ca}^{2+}$ influx trigger to signal release of otherwise fusion-competent vesicles.

\section{Conclusion and future directions}

Together, this study strongly supports a mechanistic role for the Fusl protein in regulating the voltage-gated $\mathrm{Ca}^{2+}$ channels that trigger synaptic vesicle fusion. In the absence of this regulation, active zone $\mathrm{Ca}^{2+}$ channels domains fail to form or be properly organized. Transmission is severely impaired but certainly not eliminated, indicating that Fusl facilitates $\mathrm{Ca}^{2+}$ channel domain assembly, but is not absolutely required. Ultrastructurally normal active zones persist in the complete absence of Fusl but lack the localized $\mathrm{Ca}^{2+}$ trigger for vesicle exocytosis and therefore only inefficiently manage neurotransmitter release. One possible role for the Fusl protein might be to serve as a direct interacting partner with the $\mathrm{Ca}^{2+}$ channel to enable its correct trafficking and/or localized maintenance at the active zone (Ambudkar, 2007). Fusl is not restricted to active zone domains, like the $\mathrm{Ca}^{2+}$ channel, but rather shows a diffuse presynaptic plasma membrane localization, similar to the tSNARE Syntaxin. Tests for direct association between Fusl and Cac channels have so far been inconclusive. Another model, consistent with the predicted transmembrane transporter function, is that Fusl might regulate the presynaptic environment in a way that facilitates $\mathrm{Ca}^{2+}$ channel localization. Arguing for this model, the closest human se- quence homolog, Sialin, transports sialic acid (Wreden et al., 2005; Yarovaya et al., 2005). This modified sugar group is a component of transmembrane glycoproteins, typically as the terminal residue of cell surface oligosaccharides. Misregulation of this cargo transport could be easily envisioned to cause defects in $\mathrm{Ca}^{2+}$ channel trafficking and/or maintenance during presynaptic active zone assembly. Future work will examine the molecular function of the Fuseless protein by attempting to determine whether it functions in synaptic glycosylation, perhaps as a transmembrane transporter, as predicted, and, if so, the exact nature of the transported cargo and its effects on synaptogenesis.

\section{References}

Ambudkar IS (2007) TRPC1: a core component of store-operated calcium channels. Biochem Soc Trans 35:96-100.

Andrews HK, Zhang YQ, Trotta N, Broadie K (2002) Drosophila sec10 is required for hormone secretion but not general exocytosis or neurotransmission. Traffic 3:906-921.

Aravamudan B, Broadie K (2003) Synaptic Drosophila UNC-13 is regulated by antagonistic G-protein pathways via a proteasome-dependent degradation mechanism. J Neurobiol 54:417-438.

Aravamudan B, Fergestad T, Davis WS, Rodesch CK, Broadie K (1999) Drosophila UNC-13 is essential for synaptic transmission. Nat Neurosci 2:965-971.

Becherer U, Moser T, Stuhmer W, Oheim M (2003) Calcium regulates exocytosis at the level of single vesicles. Nat Neurosci 6:846-853.

Benjamini Y, Hochberg Y (1995) Controlling the false discovery rate-a practical and powerful approach to multiple testing. JR Stat Soc Ser B 57:289-300.

Bourne Y, Dannenberg J, Pollmann V, Marchot P, Pongs O (2001) Immunocytochemical localization and crystal structure of human frequenin (neuronal calcium sensor 1). J Biol Chem 276:11949-11955.

Brand AH, Perrimon N (1993) Targeted gene expression as a means of altering cell fates and generating dominant phenotypes. Development 118:401-415.

Broadie K, Bellen HJ, DiAntonio A, Littleton JT, Schwarz TL (1994) Absence of synaptotagmin disrupts excitation-secretion coupling during synaptic transmission. Proc Natl Acad Sci USA 91:10727-10731.

Broadie K, Prokop A, Bellen HJ, O’Kane CJ, Schulze KL, Sweeney ST (1995) Syntaxin and synaptobrevin function downstream of vesicle docking in Drosophila. Neuron 15:663-673.

Buchner E (1991) Genes expressed in the adult brain of Drosophila and effects of their mutations on behavior: a survey of transmitter- and second messenger-related genes. J Neurogenet 7:153-192.

Burg MG, Sarthy PV, Koliantz G, Pak WL (1993) Genetic and molecular identification of a Drosophila histidine decarboxylase gene required in photoreceptor transmitter synthesis. EMBO J 12:911-919.

Chen YA, Scales SJ, Jagath JR, Scheller RH (2001) A discontinuous SNAP-25 C-terminal coil supports exocytosis. J Biol Chem 276:28503-28508.

Craig EA, Eisenman HC, Hundley HA (2003) Ribosome-tethered molecular chaperones: the first line of defense against protein misfolding. Curr Opin Microbiol 157:162.

Daniels RW, Collins CA, Gelfand MV, Dant J, Brooks ES, Krantz DE, DiAntonio A (2004) Increased expression of the Drosophila vesicular glutamate transporter leads to excess glutamate release and a compensatory decrease in quantal content. J Neurosci 24:10466-10474.

Deitcher DL, Ueda A, Stewart BA, Burgess RW, Kidokoro Y, Schwarz TL (1998) Distinct requirements for evoked and spontaneous release of neurotransmitter are revealed by mutations in the Drosophila gene neuronalsynaptobrevin. J Neurosci 18:2028-2039.

Del Castillo J, Katz B (1954) The failure of local-circuit transmission at the nerve-muscle junction. J Physiol (Lond) 123:7-8P.

Demuro A, Parker I (2006) Imaging single-channel calcium microdomains. Cell Calcium 40:413-422.

Dermaut B, Norga KK, Kania A, Verstreken P, Pan H, Zhou Y, Callaerts P, Bellen HJ (2005) Aberrant lysosomal carbohydrate storage accompanies endocytic defects and neurodegeneration in Drosophila benchwarmer. J Cell Biol 170:127-139.

DiAntonio A, Schwarz TL (1994) The effect on synaptic physiology of synaptotagmin mutations in Drosophila. Neuron 12:909-920.

DiAntonio A, Petersen SA, Heckmann M, Goodman CS (1999) Glutamate 
receptor expression regulates quantal size and quantal content at the Drosophila neuromuscular junction. J Neurosci 19:3023-3032.

Dodge Jr FA, Rahamimoff R (1967) Co-operative action a calcium ions in transmitter release at the neuromuscular junction. J Physiol (Lond) 193:419-432.

Farsad K, De Camilli P (2002) Neurotransmission and the synaptic vesicle cycle. Yale J Biol Med 75:261-284.

Featherstone DE, Davis WS, Dubreuil RR, Broadie K (2001) Drosophila $\alpha$ and $\beta$-spectrin mutations disrupt presynaptic neurotransmitter release. J Neurosci 21:4215-4224.

Featherstone DE, Rushton E, Rohrbough J, Liebel F, Karr J, Sheng Q, Rodesch CK, Broadie K (2005) An essential Drosophila glutamate receptor subunit that functions in both neuropil and neuromuscular junction. J Neurosci 25:3199-3208.

Fergestad T, Broadie K (2001) Interaction of stoned and synaptotagmin in synaptic vesicle endocytosis. J Neurosci 21:1218-1227.

Geppert M, Goda Y, Hammer RE, Li C, Rosahl TW, Stevens CF, Sudhof TC (1994) Synaptotagmin I: a major $\mathrm{Ca}^{2+}$ sensor for transmitter release at a central synapse. Cell 79:717-727.

Hille B (2001) Ion channels of excitable membranes. Sunderland, MA: Sinauer Associates.

Holm S (1979) A simple sequentially rejective multiple test procedure. Scand J Stat 6:65-70.

Horrigan FT, Bookman RJ (1994) Releasable pools and the kinetics of exocytosis in adrenal chromaffin cells. Neuron 13:1119-1129.

Huang FD, WoodruffE, Mohrmann R, Broadie K (2006) Rolling blackout is required for synaptic vesicle exocytosis. J Neurosci 26:2369-2379.

Johnson EC, Pak WL (1986) Electrophysiological study of Drosophila rhodopsin mutants. J Gen Physiol 88:651-673.

Katz B, Miledi R (1965) The effect of calcium on acetylcholine release from motor nerve terminals. Proc R Soc Lond B Biol Sci 161:496-503.

Katz B, Miledi R (1968) The role of calcium in neuromuscular facilitation. J Physiol (Lond) 195:481-492.

Katz B, Miledi R (1970) Further study of the role of calcium in synaptic transmission. J Physiol (Lond) 207:789-801.

Kawasaki F, Mattiuz AM, Ordway RW (1998) Synaptic physiology and ultrastructure in comatose mutants define an in vivo role for NSF in neurotransmitter release. J Neurosci 18:10241-10249.

Kawasaki F, Felling R, Ordway RW (2000) A temperature-sensitive paralytic mutant defines a primary synaptic calcium channel in Drosophila. J Neurosci 20:4885-4889.

Kawasaki F, Collins SC, Ordway RW (2002) Synaptic calcium-channel function in Drosophila: analysis and transformation rescue of temperature-sensitive paralytic and lethal mutations of cacophony. J Neurosci 22:5856-5864.

Kawasaki F, Zou B, Xu X, Ordway RW (2004) Active zone localization of presynaptic calcium channels encoded by the cacophony locus of Drosophila. J Neurosci 24:282-285.

Khvotchev MV, Ren M, Takamori S, Jahn R, Sudhof TC (2003) Divergent functions of neuronal Rab11 b in $\mathrm{Ca}^{2+}$-regulated versus constitutive exocytosis. J Neurosci 23:10531-10539.

Kidokoro Y (2003) Roles of SNARE proteins and synaptotagmin I in synaptic transmission: studies at the Drosophila neuromuscular synapse. Neurosignals $12: 13-30$.

Kiss JZ, Rougon G (1997) Cell biology of polysialic acid. Curr Opin Neurobiol 7:640-646.

Kittel RJ, Wichmann C, Rasse TM, Fouquet W, Schmidt M, Schmid A, Wagh DA, Pawlu C, Kellner RR, Willig KI, Hell SW, Buchner E, Heckmann M, Sigrist SJ (2006) Bruchpilot promotes active zone assembly, $\mathrm{Ca}^{2+}$ channel clustering, and vesicle release. Science 312:1051-1054.

Kuromi H, Kidokoro Y (2000) Tetanic stimulation recruits vesicles from reserve pool via a cAMP-mediated process in Drosophila synapses. Neuron 27:133-143.

Lam G, Thummel CS (2000) Inducible expression of double-stranded RNA directs specific genetic interference in Drosophila. Curr Biol 10:957-963.

Larivee DC, Conrad SK, Stephenson RS, Pak WL (1981) Mutation that selectively affects rhodopsin concentration in the peripheral photoreceptors of Drosophila melanogaster. J Gen Physiol 78:521-545.

Lindsley DL, Zimm GG (1992) The genome of Drosophila melanogaster. New York: Academic.

Littleton JT, Ganetzky B (2000) Ion channels and synaptic organization: analysis of the Drosophila genome. Neuron 26:35-43.
Littleton JT, Bellen HJ, Perin MS (1993) Expression of synaptotagmin in Drosophila reveals transport and localization of synaptic vesicles to the synapse. Development 118:1077-1088.

Littleton JT, Chapman ER, Kreber R, Garment MB, Carlson SD, Ganetzky B (1998) Temperature-sensitive paralytic mutations demonstrate that synaptic exocytosis requires SNARE complex assembly and disassembly. Neuron 21:401-413.

Llinas R, Steinberg IZ, Walton K (1976) Presynaptic calcium currents and their relation to synaptic transmission: voltage clamp study in squid giant synapse and theoretical model for the calcium gate. Proc Natl Acad Sci USA 73:2918-2922.

Llinas R, Sugimori M, Silver RB (1992) Microdomains of high calcium concentration in a presynaptic terminal. Science 256:677-679.

Lnenicka GA, Grizzaffi J, Lee B, Rumpal N (2006) $\mathrm{Ca}^{2+}$ dynamics along identified synaptic terminals in Drosophila larvae. J Neurosci 26:12283-12293.

Markow TA, Merriam J (1977) Phototactic and geotactic behavior of countercurrent defective mutants of Drosophila melanogaster. Behav Genet 7:447-455.

Melzig J, Burg MG, Pak WL, Buchner E (1998) Selective histamine uptake rescues photo- and mechanoreceptor function of histidine decarboxylase-deficient Drosophila mutant. J Neurosci 18:7160-7166.

Mochida S, Sheng ZH, Baker C, Kobayashi H, Catterall WA (1996) Inhibition of neurotransmission by peptides containing the synaptic protein interaction site of N-type $\mathrm{Ca}^{2+}$ channels. Neuron 17:781-788.

Morin PM, Sagne C, Gasnier B (2004) Functional characterization of wildtype and mutant human sialin. EMBO J 23:4560-4570.

Nishimune H, Sanes JR, Carlson SS (2004) A synaptic laminin-calcium channel interaction organizes active zones in motor nerve terminals. $\mathrm{Na}$ ture 432:580-587.

Ohnishi O (1977) Spontaneous and ethyl methanesulfonate-induced mutations controlling viability in Drosophila melanogaster. III. Heterozygous effect of polygenic mutations. Genetics 87:547-556.

Pak WL (1975) Mutations affecting the vision of Drosophila melanogaster. In: Handbook of genetics, Vol 3 (King RC, ed), pp 703-733. New York: Plenum.

Pak WL (1995) Drosophila in vision research. The Friedenwald Lecture. Invest Ophthalmol Vis Sci 36:2340-2357.

Pak WL, Leung H-T (2003) Genetic approaches to visual transduction in Drosophila melanogaster. Receptors Channels 9:149-167.

Pan CY, Jeromin A, Lundstrom K, Yoo SH, Roder J, Fox AP (2002) Alterations in exocytosis induced by neuronal $\mathrm{Ca}^{2+}$ sensor-1 in bovine chromaffin cells. J Neurosci 22:2427-2433.

Pongs O (1993) Structure-function studies on the pore of potassium channels. J Membr Biol 136:1-8.

Richmond JE, Broadie KS (2002) The synaptic vesicle cycle: exocytosis and endocytosis in Drosophila and C. elegans. Curr Opin Neurobiol 12:499-507.

Rizo J, Sudhof TC (2002) Snares and Munc18 in synaptic vesicle fusion. Nat Rev Neurosci 3:641-653.

Rohrbough J, Pinto S, Mihalek RM, Tully T, Broadie K (1999) latheo, a Drosophila gene involved in learning, regulates functional synaptic plasticity. Neuron 23:55-70.

Sheng ZH, Westenbroek RE, Catterall WA (1998) Physical link and functional coupling of presynaptic calcium channels and the synaptic vesicle docking/fusion machinery. J Bioenerg Biomembr 30:335-345.

Sippy T, Cruz-Martin A, Jeromin A, Schweizer FE (2003) Acute changes in short-term plasticity at synapses with elevated levels of neuronal calcium sensor-1. Nat Neurosci 6:1031-1038.

Speese SD, Trotta N, Rodesch CK, Aravamudan B, Broadie K (2003) The ubiquitin proteasome system acutely regulates presynaptic protein turnover and synaptic efficacy. Curr Biol 13:899-910.

Stewart BA, Atwood HL, Renger JJ, Wang J, Wu CF (1994) Improved stability of Drosophila larval neuromuscular preparations in haemolymphlike physiological solutions. J Comp Physiol 2:179-191.

Suzuki DT, Procunier D (1969) Temperature-sensitive mutations in Drosophila melanogaster. 3. Dominant lethals and semilethals on chromosome 2. Proc Natl Acad Sci USA 62:369-376.

Takamori S, Holt M, Stenius K, Lemke EA, Gronborg M, Riedel D, Urlaub H, Schenck S, Brügger B, Ringler P, Müller SA, Rammner B, Gräter F, Hub JS, De Groot BL, Mieskes G, Moriyama Y, Klingauf J, Grubmüller H, 
Heuser J, et al. (2006) Molecular anatomy of a trafficking organelle. Cell 127:831-846.

Trotta N, Rodesch CK, Fergestad T, Broadie K (2004) Cellular bases of activity-dependent paralysis in Drosophila stress-sensitive mutants. J Neurobiol 60:328-347.

Tsujimoto T, Jeromin A, Saitoh N, Roder JC, Takahashi T (2002) Neuronal calcium sensor 1 and activity-dependent facilitation of P/Q-type calcium currents at presynaptic nerve terminals. Science 295:2276-2279.

Verheijen FW, Verbeek E, Aula N, Beerens C, Havelaar A, Joosse M, Peltonen L, Aula P, Galjaard H, van der Spek P, Mancini G (1999) A new gene, encoding an anion transporter, is mutated in sialic acid storage diseases. Nat Genet 23:462-465.

Von Schilcher F (1976) The behavior of cacophony, a courtship song mutant in Drosophila melanogaster. Behav Biol 17:187-196.

Wagh DA, Rasse TM, Asan E, Hofbauer A, Schwenkert I, Durrbeck H, Buchner S, Dabauvalle MC, Schmidt M, Qin G, Wichmann C, Kittel R, Sigrist SJ, Buchner E (2006) Bruchpilot, a protein with homology to ELKS/ CAST, is required for structural integrity and function of synaptic active zones in Drosophila. Neuron 49:833-844.

Wang CY, Yang F, He X, Chow A, Du J, Russell JT, Lu B (2001) $\mathrm{Ca}^{2+}$ binding protein frequenin mediates GDNF-induced potentiation of $\mathrm{Ca}^{2+}$ channels and transmitter release. Neuron 32:99-112.

Wreden CC, Wlizla M, Reimer RJ (2005) Varied mechanisms underlie the free sialic acid storage disorders. J Biol Chem 280:1408-1416.

Wu MN, Fergestad T, Lloyd TE, He Y, Broadie K, Bellen HJ (1999) Syntaxin
$1 \mathrm{~A}$ interacts with multiple exocytic proteins to regulate neurotransmitter release in vivo. Neuron 23:593-605.

Xing B, Ashleigh Long A, Harrison DA, Cooper RL (2005) Developmental consequences of neuromuscular junctions with reduced presynaptic calcium channel function. Synapse 57:132-147.

Yarovaya N, Schot R, Fodero L, McMahon M, Mahoney A, Williams R, Verbeek E, de Bondt A, Hampson M, van der Spek P, Stubbs A, Masters CL, Verheijen FW, Mancini GM, Venter DJ (2005) Sialin, an anion transporter defective in sialic acid storage diseases, shows highly variable expression in adult mouse brain, and is developmentally regulated. Neurobiol Dis 19:351-365.

Yoshihara M, Littleton JT (2002) Synaptotagmin I functions as a calcium sensor to synchronize neurotransmitter release. Neuron 36:897-908.

Yoshihara M, Suzuki K, Kidokoro Y (2000) Two independent pathways mediated by cAMP and protein kinase A enhance spontaneous transmitter release at Drosophila neuromuscular junctions. J Neurosci 20:8315-8322.

Zhang YQ, Bailey AM, Matthies HJ, Renden RB, Smith MA, Speese SD, Rubin GM, Broadie K (2001) Drosophila fragile X-related gene regulates the MAP1B homolog Futsch to control synaptic structure and function. Cell 107:591-603.

Zucker RS (1993) Calcium and transmitter release at nerve terminals. Biochem Soc Trans 21:395-401.

Zucker RS (1996) Exocytosis: a molecular and physiological perspective. Neuron 17:1049-1055. 